Virginia Commonwealth University VCU Scholars Compass

2014

\title{
Aluminum Zintl anion moieties within sodium aluminum clusters
}

\author{
Haopeng Wang \\ Johns Hopkins University \\ Xinxing Zhang \\ Johns Hopkins University \\ Yeon Jae Ko \\ Johns Hopkins University \\ See next page for additional authors
}

Follow this and additional works at: http://scholarscompass.vcu.edu/phys_pubs

Part of the Physics Commons

Wang, H., Zhang, X., Ko, Y., et al. Aluminum Zintl anion moieties within sodium aluminum clusters. The Journal of Chemical Physics, 140, 054301 (2014). Copyright (C) 2014 AIP Publishing LLC.

\section{Downloaded from}

http://scholarscompass.vcu.edu/phys_pubs/107

This Article is brought to you for free and open access by the Dept. of Physics at VCU Scholars Compass. It has been accepted for inclusion in Physics Publications by an authorized administrator of VCU Scholars Compass. For more information, please contact libcompass@vcu.edu. 


\section{Authors}

Haopeng Wang, Xinxing Zhang, Yeon Jae Ko, Andrej Grubisic, Xiang Li, Gerd Gantefoer, Hansgeorg

Schnoeckel, Bryan W. Eichhorn, Mal-Soon Lee, Puru Jena, Anil K. Kandalam, Boggavarapu Kiran, and Kit H. Bowen Jr. 


\title{
Aluminum Zintl anion moieties within sodium aluminum clusters
}

\author{
Haopeng Wang, ${ }^{1}$ Xinxing Zhang, ${ }^{1}$ Yeon Jae Ko, ${ }^{1}$ Andrej Grubisic, ${ }^{1}$ Xiang Li, ${ }^{1}$ \\ Gerd Ganteför, ${ }^{1}$ Hansgeorg Schnöckel, ${ }^{2}$ Bryan W. Eichhorn, ${ }^{3}$ Mal-Soon Lee, ${ }^{4}$ P. Jena, ${ }^{4}$ \\ Anil K. Kandalam, ${ }^{5, \text { a) }}$ Boggavarapu Kiran, ${ }^{6, \text { a) }}$ and Kit H. Bowen ${ }^{1, a)}$ \\ ${ }^{1}$ Department of Chemistry, Johns Hopkins University, Baltimore, Maryland 21218, USA \\ ${ }^{2}$ Institute of Inorganic Chemistry, Karlsruhe Institute of Technology, 76128 Karlsruhe, Germany \\ ${ }^{3}$ Department of Chemistry, University of Maryland at College Park, College Park, Maryland 20742, USA \\ ${ }^{4}$ Department of Physics, Virginia Commonwealth University, Richmond, Virginia 23284, USA \\ ${ }^{5}$ Department of Physics, West Chester University of Pennsylvania, West Chester, Pennsylvania 19383, USA \\ ${ }^{6}$ Department of Chemistry, McNeese State University, Lake Charles, Louisiana 70609, USA
}

(Received 26 November 2013; accepted 10 January 2014; published online 3 February 2014)

\begin{abstract}
Through a synergetic combination of anion photoelectron spectroscopy and density functional theory based calculations, we have established that aluminum moieties within selected sodium-aluminum clusters are Zintl anions. Sodium-aluminum cluster anions, $\mathrm{Na}_{\mathrm{m}} \mathrm{Al}_{\mathrm{n}}{ }^{-}$, were generated in a pulsed arc discharge source. After mass selection, their photoelectron spectra were measured by a magnetic bottle, electron energy analyzer. Calculations on a select sub-set of stoichiometries provided geometric structures and full charge analyses for both cluster anions and their neutral cluster counterparts, as well as photodetachment transition energies (stick spectra), and fragment molecular orbital based correlation diagrams. (C) 2014 AIP Publishing LLC. [http://dx.doi.org/10.1063/1.4862989]
\end{abstract}

\section{INTRODUCTION}

Zintl phases are typically solid state, salt-like $\mathrm{A}_{\mathrm{a}} \mathrm{X}_{\mathrm{x}}$ compounds formed from electropositive elements, $\mathrm{A}$, and somewhat electronegative main-group elements, $\mathrm{X} .{ }^{1,2}$ Zintl phases are differentiated from traditional inter-metallics and semiconductors by their salt-like character, i.e., $\mathrm{A}^{+}$and $\mathrm{X}^{-}$, and the presence of substantial $\mathrm{X}-\mathrm{X}$ bonding. ${ }^{3}$ The prototypical Zintl phase, $\mathrm{NaTl}$, is best described as a $\left(\mathrm{Na}^{+}\right)\left(\mathrm{Tl}^{-}\right)$salt containing a $\left[\mathrm{Tl}^{-}\right]$network, where the thallium anions form a diamond lattice with direct $\mathrm{Tl}-\mathrm{Tl}$ bonds. ${ }^{4}$

Zintl anions are multiply negatively charged polyatomic aggregates of main group elements and are often associated with the solution-based chemistry of naked clusters, e.g., $\mathrm{Sn}_{5}{ }^{2-}, \mathrm{Sb}_{7}{ }^{3-}, \mathrm{Pb}_{9}{ }^{4-}$, and $\mathrm{Bi}_{4}{ }^{2-} .5$ As in Zintl phases, Zintl anions are also characterized by $\mathrm{X}-\mathrm{X}$ bonding. In addition, Zintl anions often have "pseudo-atom" equivalents as described by Klemm. ${ }^{6}$ For example, $\mathrm{As}_{8}{ }^{8-}$ and $\mathrm{Sb}_{8}{ }^{8-}$ are isoelectronic and isostructural to the $\mathrm{S}_{8}$ rings in elemental sulfur. ${ }^{7,8}$ Most Zintl anions display multi-center, multi-electron bonding, and they can be described by the electronic counting principles developed for the boron hydrides. ${ }^{5}$ For example, $\mathrm{Ge}_{9}{ }^{4-}$ and $\mathrm{Pb}_{10}{ }^{2-}$ have nido and closo deltahedral structures, ${ }^{9,10}$ respectively, as predicted from Wade's rules of electron counting. While Zintl anions are most commonly associated with the heavier main group elements ( $\geq$ period 4 ), clusters of the 3 rd period are also known, e.g., $\mathrm{Si}_{9}{ }^{3-14-}$ and $\mathrm{P}_{7}{ }^{3-}$. 5, 11,12

Although most studies on Zintl anions have been conducted in condensed phases, there is also a growing body of work in the gas phase. There, Zintl anions occur as Zintl moieties within larger clusters, the net charge state of which is

\footnotetext{
a) Authors to whom correspondence should be addressed. Electronic addresses: AKandalam@wcupa.edu, kiran@mcneese.edu, and kbowen@jhu.edu
}

determined by the number of complementary cationic moieties present. For example, Zintl anions in clusters were first implicated in photoionization mass spectral studies of III-V and IV-V intermetallic clusters. ${ }^{13}$ Additionally, the presence of the $\mathrm{Bi}_{3}{ }^{3-}$ Zintl anion was inferred from the observation of $\left(\mathrm{Na}_{4} \mathrm{Bi}_{3}\right)^{+}$as a magic number species in mass spectra. ${ }^{13,14}$ The occurrence of the Zintl anions: $\mathrm{Sn}_{4}{ }^{4-}, \mathrm{Ga}_{4}{ }^{2-}, \mathrm{Sn}_{12}{ }^{2-}$, and $\mathrm{Pb}_{12}{ }^{2-}$ within the cluster anions: $\left(\mathrm{Na}_{4} \mathrm{Sn}_{4}\right)^{-},\left(\mathrm{NaGa}_{4}\right)^{-}$, $\left(\mathrm{KSn}_{12}\right)^{-}$, and $\left(\mathrm{KPb}_{12}\right)^{-}$, respectively, has also been shown through the combination of anion photoelectron experiments and theoretical calculations. ${ }^{15-18}$ Furthermore, the existence of Zintl anions in several endohedral cage clusters, such as $\left[\mathrm{M} @ \mathrm{~Pb}_{12}\right]^{2-}$ and $\mathrm{M} @\left(\mathrm{Sn}_{12}\right)^{-}$, where $\mathrm{M}$ is a transition metal atom, has also been inferred. ${ }^{19-22}$

Interestingly, Zintl anions of aluminum have not been prepared in solution or solid phases. Although LiAl is isoelectronic and isostructural with the prototypical Zintl phase, $\mathrm{NaTl}$, early theoretical studies showed limited charge transfer between lithium and aluminum, thus deviating from the traditional definition of a Zintl phase. ${ }^{23-25}$ More recent studies, however, have shown substantial $\mathrm{Al}-\mathrm{Al}$ interactions in an $\left[\mathrm{Al}^{-}\right]$network structure with bonding motifs that conform to the Zintl-Klemm concept of a Zintl phase. ${ }^{3,26}$ Nevertheless, with few exceptions, ${ }^{3,27}$ most solid compounds of aluminum with alkali metals have not been classified as Zintl phases.

In the condensed phase, aluminum clusters are more commonly found in the form of low oxidation state "metalloid clusters" as described by Schnoeckel. ${ }^{28}$ While there are significant similarities between Zintl ions and metalloid clusters, there are defining differences as well. For example, Zintl ions are anionic and have elemental oxidation states of less than zero. In contrast, the metalloids contain elements with oxidation states greater than zero but less than the maximum valence state of the element. Nevertheless, while standalone aluminum Zintl anions are not known in condensed 
phases, aluminum Zintl anion subunits can be found in some metalloid clusters. The recently reported $\left[\mathrm{Al}(\mathrm{O}-t-\mathrm{Bu})_{3}\right]_{6} \mathrm{Al}_{6}{ }^{8-}$ metalloid ${ }^{29}$ contains an $\mathrm{Al}_{6}{ }^{8-}$ core that has Zintl-like characteristics, suggesting that substituted or stabilized aluminum Zintl clusters may be viable.

Further insight into the viability of aluminum Zintl cluster moieties can be gleaned through studies of aluminumcontaining, gas phase clusters. Several such systems have already been examined both experimentally and theoretically. The aluminum cluster anion, $\mathrm{Al}_{13}{ }^{-}$has received substantial attention because of its unusual stability, which derives both from its electronic (a 40 valence electron shell closing) and its geometric structure (an icosahedron). ${ }^{30,31}$ The ionic character of $\mathrm{KAl}_{13}$, i.e., $\mathrm{K}^{+}$and $\mathrm{Al}_{13}{ }^{-}$, was theoretically predicted ${ }^{32-34}$ and later experimentally confirmed by both photoionization ${ }^{35,36}$ of $\mathrm{KAl}_{13}$ and anion photoelectron experiments ${ }^{37,38}$ of $\left(\mathrm{KAl}_{13}\right)^{-}$. Although $\mathrm{Al}_{13}{ }^{-}$is not multiply charged and differs in that way from traditional Zintl anions, $\mathrm{KAl}_{13}$ can be seen as a 14-atom, "diatomic," ionic "molecule" and as such, as the basic unit of a hypothetical aluminumbased "Zintl phase." Cluster anions, $\left(\mathrm{LiAl}_{\mathrm{n}}\right)^{-}(\mathrm{n}=3-13)$ and $\left(\mathrm{CuAl}_{n}\right)^{-}(\mathrm{n}=2-15)$, were also investigated by anion photoelectron spectroscopy, where interest in the formation of salt-like structures motivated those studies. ${ }^{39,40}$ To further investigate their bonding motifs, studies of all-metal aromaticity (and anti-aromaticity) were also carried out on $\left(\mathrm{MAl}_{4}\right)^{-}$ (where $\mathrm{M}=\mathrm{Li}, \mathrm{Na}$, and $\mathrm{Cu}$ ), on $\left(\mathrm{MAl}_{6}\right)^{-}$(where $\mathrm{M}=\mathrm{Li}, \mathrm{Na}$, $\mathrm{K}, \mathrm{Cu}$, and $\mathrm{Au}$ ), and on $\left(\mathrm{Li}_{3} \mathrm{Al}_{4}\right)^{-}$cluster anions ${ }^{41-43}$ by using a combination of anion photoelectron spectroscopy and theoretical calculations. Several mixed sodium-aluminum clusters and their anions were also studied through theoretical calculations. ${ }^{44}$ Recently, the isolated, multiply charged aluminum cluster anions, $\mathrm{Al}_{\mathrm{n}}{ }^{2-}$ and $\mathrm{Al}_{\mathrm{n}}{ }^{3-}$, were formed by electron attachment to gas phase, singly charged aluminum cluster anions in a Penning trap; there, the smallest observed sizes were $\mathrm{n}=38$ and 103 , respectively. ${ }^{45}$ Taken together, these experimental and computational studies of doped or pure aluminum clusters in gas phase have laid the foundation for exploring multiply charged, aluminum Zintl cluster anion moieties within larger clusters.

One can imagine a salt-like lattice made up of aluminum cluster anions and counter cations. Calculations, however, suggest that such a lattice, when composed of $\mathrm{K}^{+}$and $\mathrm{Al}_{13}{ }^{-}$ ions, would not be stable. ${ }^{33}$ On the other hand, if such a lattice were composed, not of singly charged aluminum cluster anions, but instead of multiply charged, aluminum cluster anions, i.e., aluminum Zintl anions, with an appropriate number of complementary cations, then a substantially greater lattice stabilization energy could be achieved. Under those circumstances, the formation of a bulk ionic material, i.e., a clusterassembled material might be feasible. A first step in exploring this possibility involves assessing whether aluminum Zintl anion moieties can exist within mixed alkali metal-aluminum clusters.

Here, we present a combined experimental and theoretical study aimed at determining whether multiply charged, aluminum Zintl anionic moieties are formed within sodiumaluminum clusters. On the experimental side, anion photoelectron spectroscopic measurements were carried out on size-selected, sodium-doped aluminum cluster anions, $\mathrm{Na}_{\mathrm{m}} \mathrm{Al}_{\mathrm{n}}{ }^{-}$. The results of these experiments pertain both to the anionic clusters and to their corresponding neutral clusters. To better understand the various properties of mixed sodium/aluminum clusters, calculations based on density functional theory (DFT) were also carried out both on the cluster anions and their neutral cluster counterparts. In addition to calculating photodetachment (photoelectron) transition energies for the cluster anions and geometric structures for both the cluster anions and their neutral counterparts, we also conducted full charge analyses through Natural Population Analysis (NPA), for both the cluster anions and their corresponding neutral clusters. Calculated photodetachment transition energies were compared with measured transitions in the photoelectron spectra. Geometric structures revealed the sub-structure of the aluminum cluster moieties and how the sodium atoms were arranged around them. Natural population analyses illuminated the extent of Zintl anion character in the aluminum moieties within these clusters. As such, NPA was our primary tool for identifying Zintl anion character in specific aluminum cluster moieties. Among the many sodium-aluminum cluster anions that we generated and studied by photoelectron spectroscopy, five stoichiometries and their neutral counterparts were selected to undergo the detailed theoretical analysis described above. These were $\mathrm{Na}_{2} \mathrm{Al}_{6}{ }^{-}, \mathrm{Na}_{4} \mathrm{Al}_{5}{ }^{-}, \mathrm{Na}_{5} \mathrm{Al}_{5}{ }^{-}, \mathrm{Na}_{3} \mathrm{Al}_{12}{ }^{-}$, and $\mathrm{Na}_{4} \mathrm{Al}_{12}{ }^{-}$as well as their neutral counterparts, $\mathrm{Na}_{2} \mathrm{Al}_{6}$, $\mathrm{Na}_{4} \mathrm{Al}_{5}, \mathrm{Na}_{5} \mathrm{Al}_{5}, \mathrm{Na}_{3} \mathrm{Al}_{12}$, and $\mathrm{Na}_{4} \mathrm{Al}_{12}$, respectively. These stoichiometries were chosen in part because they are all closed shell species ${ }^{46}$ in either their anion or their neutral charge states. As closed shells, they would be expected to exhibit enhanced stability. The degree to which particular cluster stoichiometries conformed to the expectations of the shell model was explored through fragment molecular orbital (FMO) calculations and their resultant correlation diagrams. ${ }^{47}$

\section{METHODS}

\section{A. Experimental}

Anion photoelectron spectroscopy is conducted by crossing a mass-selected beam of negative ions with a fixed-frequency photon beam and energy-analyzing the resultant photodetached electrons. It is governed by the energyconserving relationship, $\mathrm{h} v=\mathrm{EBE}+\mathrm{EKE}$, where $\mathrm{h} v$ is the photon energy, EBE is the electron binding (transition) energy, and EKE is the electron kinetic energy. Briefly, our apparatus, which has been described previously, ${ }^{48}$ consists of a pulsed arc cluster ionization source (PACIS), ${ }^{49}$ a time-of flight mass spectrometer for mass analysis and mass selection, a Nd:YAG laser operated in these experiments at its third harmonic wavelength ( $355 \mathrm{~nm}, 3.49 \mathrm{eV} /$ photon) for photodetachment, and a magnetic bottle, electron energy analyzer with a resolution of $30 \mathrm{meV}$ at $\mathrm{EKE}=1 \mathrm{eV}$. The photoelectron spectra were calibrated against the well-known photoelectron spectrum of $\mathrm{Cu}^{-} .50$

In our pulsed arc cluster ionization source, a discharge is triggered between an anode and a grounded, conductive, sample cathode, while helium gas from a pulsed valve 
is fed through the discharge region. In the present study, the sample cathode consists of an aluminum rod, with a cup-like depression on top, into which a mixture of aluminum powder and particles of sodium metal had been pressed into a disk. The sample material is vaporized by the discharge, cooled by the helium jet, and forms cluster anions as it travels down a $20 \mathrm{~cm}$ tube into high vacuum. The resulting cluster anions are then extracted, mass analyzed, and mass selected prior to being irradiated by photons.

\section{B. Computational}

Density functional theory based electronic structure calculations on $\mathrm{Na}_{2} \mathrm{Al}_{6}, \mathrm{Na}_{4} \mathrm{Al}_{5}, \mathrm{Na}_{5} \mathrm{Al}_{5}, \mathrm{Na}_{3} \mathrm{Al}_{12}$, and $\mathrm{Na}_{4} \mathrm{Al}_{12}$ clusters and their anions were carried out using the Gaussian03 program. ${ }^{51}$ The B3LYP functional form and the $6-311+\mathrm{G}^{*}$ basis set were used for all the calculations. The reliability of the theoretical method and the basis set used in this study had been established in a previous study on $\mathrm{MAl}_{6}{ }^{-}$ $\left(\mathrm{M}=\mathrm{Li}, \mathrm{Na}, \mathrm{K}, \mathrm{Cu}\right.$, and $\mathrm{Au}$ ) bi-metallic clusters. ${ }^{42}$ During the geometry optimizations, the convergence criterion for energy was set to $10^{-9}$ hartree, while the gradient was converged to $10^{-4}$ hartree/A. The vibrational frequencies of the reported isomers were calculated and found to be positive, indicating that these isomers are all minima on the potential energy surface. NPA, as implemented in the Gaussian03 code, were also carried out to determine the charge distributions in these clusters. The FMO of these five closed shell clusters were calculated at PW91/TZ2P using Amsterdam Density Functional Program. ${ }^{52-54}$

\section{RESULTS AND DISCUSSION}

The photoelectron spectra of all the $\mathrm{Na}_{\mathrm{m}} \mathrm{Al}_{\mathrm{n}}{ }^{-}$cluster anions measured in this study are presented in Figure 1. They were recorded using third harmonic $(355 \mathrm{~nm}, 3.49 \mathrm{eV})$ photons from a Nd:YAG laser. The electron binding energies (EBE) of the peaks in each spectrum provide the photodetachment transition energies from the ground electronic state of the cluster anion to the ground and excited electronic states of the cluster anion's neutral counterpart. The EBE value near the onset (threshold) of the lowest EBE peak in a given photoelectron spectrum was taken as an estimate of the adiabatic electron affinity, EA, of the anion's neutral counterpart. The EBE value at the intensity maximum in the lowest EBE peak in the spectrum is the vertical detachment energy, VDE, which reflects the maximum Franck-Condon overlap between the wave functions of the anion's electronic ground state and the neutral's electronic ground state at the geometry of the anion.

Note that when neutral $\mathrm{Na}_{\mathrm{m}} \mathrm{Al}_{\mathrm{n}}$ clusters exhibit closed electronic shell, with magic numbers of valence electrons, e.g., .. 8 8, 18, 20, 34, 40, 58 ..., the onset EBE values (estimated EA values) in their anions' photoelectron spectra tend to be smaller than those of their similar size neighbors. Additionally, the spacings between the lowest EBE and the next higher EBE peaks (the neutral clusters' HOMO-LUMO gaps) tend to be larger than those of their neighbors. On the other hand, when $\mathrm{Na}_{\mathrm{m}} \mathrm{Al}_{\mathrm{n}}{ }^{-}$cluster anions have closed electronic shell with magic number of valence electrons, their onset EBE values are higher than those of their similar size neighbors. In Figure 1, neutral closed shell $\mathrm{Na}_{\mathrm{m}} \mathrm{Al}_{\mathrm{n}}$ clusters are marked with "n," while "a" closed shell $\mathrm{Na}_{\mathrm{m}} \mathrm{Al}_{\mathrm{n}}{ }^{-}$anions.

As described above, we have selected five of these $\mathrm{Na}_{\mathrm{m}} \mathrm{Al}_{\mathrm{n}}{ }^{-}$cluster anions and their neutral cluster counterparts for detailed computational scrutiny. These cluster anion/neutral cluster systems are: $\mathrm{Na}_{2} \mathrm{Al}_{6}{ }^{-} / \mathrm{Na}_{2} \mathrm{Al}_{6}$, $\mathrm{Na}_{4} \mathrm{Al}_{5}{ }^{-} / \mathrm{Na}_{4} \mathrm{Al}_{5}, \mathrm{Na}_{5} \mathrm{Al}_{5}{ }^{-} / \mathrm{Na}_{5} \mathrm{Al}_{5}, \mathrm{Na}_{3} \mathrm{Al}_{12}{ }^{-} / \mathrm{Na}_{3} \mathrm{Al}_{12}$, and $\mathrm{Na}_{4} \mathrm{Al}_{12}{ }^{-} / \mathrm{Na}_{4} \mathrm{Al}_{12}$. Our calculations provided both the vertical detachment energy and the adiabatic detachment energy, $\mathrm{ADE}$, for each of these anions, where ADE is the energy difference between the ground state geometry of the anionic cluster and the structurally similar/identical isomer (nearest local minimum) of its neutral counterpart. When the neutral and its anion have similar geometries, $\mathrm{ADE}=\mathrm{EA}$. Since our calculations show this structural similarity to be the case in the systems studied here, with the possible exception of the $\mathrm{Na}_{4} \mathrm{Al}_{12}{ }^{-} / \mathrm{Na}_{4} \mathrm{Al}_{12}$ pair, the computed $\mathrm{ADE}$ value can be compared with the experimental EBE value at the spectral threshold, i.e., its estimated EA value. Table I presents both calculated and measured values of VDE and of ADE/EA.

Below, the five designated cluster anion/neutral cluster systems are presented and discussed in turn. In each case, we first present the calculated geometric structures of the lowest energy isomers of the cluster anion and its neutral cluster counterpart along with the natural population analysis for each structure. The extent of Zintl anion character in the aluminum moieties is then discussed in terms of their charge analyses. Next, we present the cluster anion's photoelectron spectrum along with its stick spectrum, the latter reflecting the calculated photodetachment transitions from the cluster anions' lowest energy isomers. Finally, we provide FMO correlation diagrams that support the closed electronic shell character of that particular cluster anion or its neutral counterpart.

\section{A. $\mathrm{Na}_{2} \mathrm{Al}_{6}-/ \mathrm{Na}_{2} \mathrm{Al}_{6}$}

Figure 2 presents the calculated structures of the three lowest energy isomers of $\mathrm{Na}_{2} \mathrm{Al}_{6}{ }^{-}$and $\mathrm{Na}_{2} \mathrm{Al}_{6}$ clusters. The most stable isomers, for both the anion and the neutral, are found to be $\mathrm{Al}_{6}$ prisms with their two sodium atoms capping the faces of the two adjacent four-member rings (see structures, $\mathbf{1}$ and $\mathbf{4})$. The structures of the second ( $\mathbf{2}$ and $\mathbf{5}$ ) and third $(3$ and 6) lowest energy isomers, which are $0.12(0.10) \mathrm{eV}$ and $0.16(0.14) \mathrm{eV}$ higher in energy than the corresponding lowest energy anion (neutral), are made up of $\mathrm{Al}_{6}$ octahedra differing only in the positions of their sodium atoms over the surface of the cluster. Note that the $\mathrm{Al}_{6}$ units (prism and octahedra) within the cluster anions are distorted relative to those within their corresponding neutral clusters. This is the result of the extra electron interacting with the $\mathrm{Al}_{6}$ unit in each anionic isomer.

Since alkali metal atoms are significantly more electropositive than aluminum atoms, one might expect considerable charge transfer, formally $1 e$, from each sodium atom to the aluminum cluster moiety, leading to $\left(\mathrm{Na}^{+}\right)_{2}\left(\mathrm{Al}_{6}{ }^{2-}\right)$ in the 

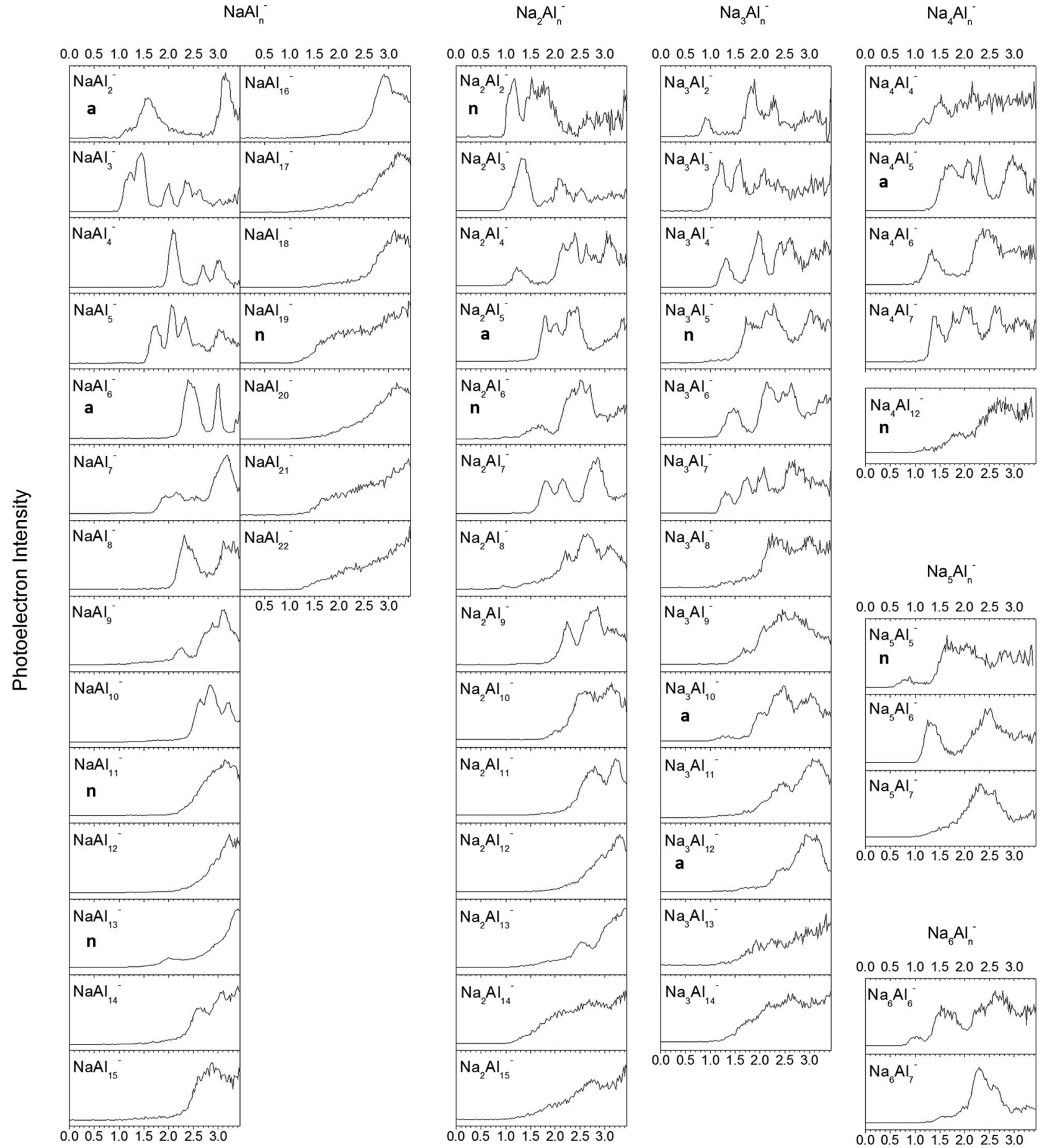

\section{Electron Binding Energy (eV)}

FIG. 1. Photoelectron spectra of $\mathrm{Na}_{\mathrm{m}} \mathrm{Al}_{\mathrm{n}}{ }^{-}$cluster anions, $(\mathrm{m}=1, \mathrm{n}=2-22 ; \mathrm{m}=2, \mathrm{n}=2-15 ; \mathrm{m}=3, \mathrm{n}=2-14 ; \mathrm{m}=4, \mathrm{n}=4-7$ and $12 ; \mathrm{m}=5$, $\mathrm{n}=5-7 ; \mathrm{m}$ $=6, \mathrm{n}=6-7)$. Species with closed shell neutrals are marked by " $\mathrm{n}$," and those with closed shell anions are marked by "a." Note that the valence electrons for these closed shell clusters, based on the jellium model, are 8, 18, 20, 34, 40, and 58.

case of the $\mathrm{Na}_{2} \mathrm{Al}_{6}$ neutral cluster. However, our NPA charge distribution analysis shows that a smaller amount of negative charge is actually transferred. In isomer $\mathbf{4}$, both sodium atoms together donate $-1.54 e$, instead of $-2.0 e$, to $\mathrm{Al}_{6}$ prism (see Figure 2). With a charge of $-1.54 e$, we classify the $\mathrm{Al}_{6}$ moiety as an incipient Zintl anion. In the case of the $\mathrm{Na}_{2} \mathrm{Al}_{6}{ }^{-}$ cluster anion, where the net charge on the entire cluster is, by definition, $-1 e$ and where the $\mathrm{Al}_{6}$ moiety holds the lion's share of the negative charge $(-2.32 e$ in isomer $\mathbf{1})$, the two sodium atoms together contribute less negative charge to the aluminum moiety than they did in the case of the $\mathrm{Na}_{2} \mathrm{Al}_{6}$ neutral cluster. Interestingly, among the isomers of $\mathrm{Na}_{2} \mathrm{Al}_{6}{ }^{-}$, as 


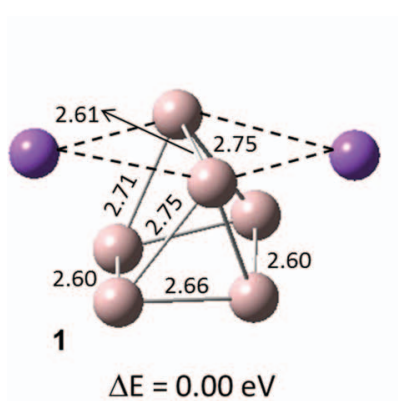

2Na: 1.32e, 6Al: $-2.32 e$

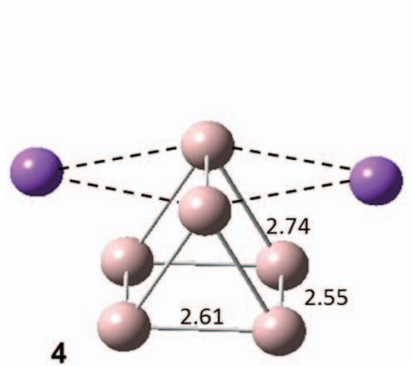

$\Delta \mathrm{E}=0.00 \mathrm{eV}$

2Na: 1.54e, 6Al: $-1.54 e$

$\mathrm{Na}_{2} \mathrm{Al}_{6}-$ Anion

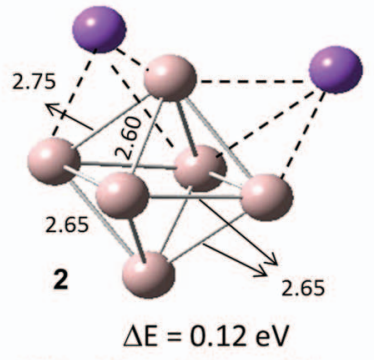

2Na: 1.20e, 6Al: $-2.20 e$

$\mathrm{Na}_{2} \mathrm{Al}_{6}$ Neutral

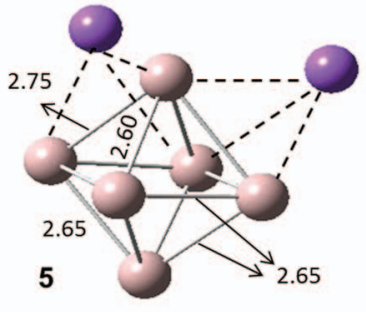

$\Delta \mathrm{E}=0.10 \mathrm{eV}$

2Na: 1.50e, 6Al: $-1.50 e$

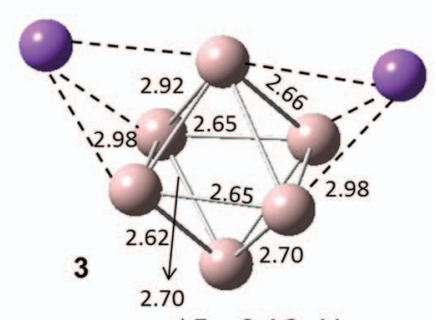

$\Delta \mathrm{E}=0.16 \mathrm{eV}$

2Na: 1.23e, 6Al: $-2.23 e$

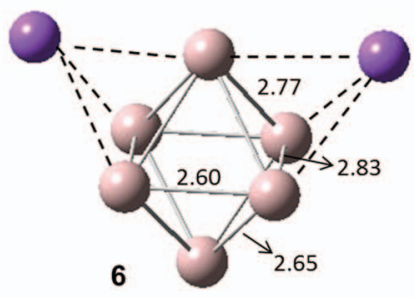

$\Delta \mathrm{E}=0.14 \mathrm{eV}$

2Na: 1.54e, 6Al: $-1.54 e$

FIG. 2. The three lowest energy isomers of the $\mathrm{Na}_{2} \mathrm{Al}_{6}{ }^{-}$cluster anion and the $\mathrm{Na}_{2} \mathrm{Al}_{6}$ neutral cluster along with their relative energies, $\Delta \mathrm{E}$ (eV). Isomers 1-3 correspond to the $\mathrm{Na}_{2} \mathrm{Al}_{6}{ }^{-}$anion, while 4-6 correspond to the lowest energy isomers of neutral $\mathrm{Na}_{2} \mathrm{Al}_{6}$. The gray spheres represent aluminum atoms and the purple spheres represent sodium atoms. All the bond lengths are given in Å. The calculated Natural Population Analysis (NPA) charges are given in italics below each isomer.

well as among those of $\mathrm{Na}_{2} \mathrm{Al}_{6}$, the extent of charge transfer to their respective $\mathrm{Al}_{6}$ moieties is similar, even though the geometries of the $\mathrm{Al}_{6}$ moieties vary from isomer to isomer.

Figure 3 presents the photoelectron spectrum of the $\mathrm{Na}_{2} \mathrm{Al}_{6}{ }^{-}$cluster anion. The first two photodetachment transitions have been calculated for each of the three lowest energy isomers of the $\mathrm{Na}_{2} \mathrm{Al}_{6}{ }^{-}$anion (1-3), and these are presented as stick spectra in Figure 3 (solid, dashed, and dotted sticks are for transitions from $\mathbf{1}, \mathbf{2}$, and $\mathbf{3}$, respectively). Focusing on the lower energy transition, the calculated values of $\mathrm{ADE}$ and VDE for isomers $1(1.20 \mathrm{eV}$ and $1.63 \mathrm{eV}), 2(1.18 \mathrm{eV}$ and $1.47 \mathrm{eV})$, and $\mathbf{3}(1.14 \mathrm{eV}$ and $1.41 \mathrm{eV})$ compare well with the experimentally determined EA and VDE values of 1.20 and $1.66 \mathrm{eV}$, respectively (see Table I). Based on the calculated and measured values, it appears that all three anionic isomers may be present in the beam. Since neutral $\mathrm{Na}_{2} \mathrm{Al}_{6}$ is a closed

TABLE I. Experimental EA and theoretical ADE values of $\mathrm{Na}_{2} \mathrm{Al}_{6}$, $\mathrm{Na}_{4} \mathrm{Al}_{5}, \mathrm{Na}_{5} \mathrm{Al}_{5}, \mathrm{Na}_{3} \mathrm{Al}_{12}$, and $\mathrm{Na}_{4} \mathrm{Al}_{12}$ neutral clusters and VDE values of $\mathrm{Na}_{2} \mathrm{Al}_{6}{ }^{-}, \mathrm{Na}_{4} \mathrm{Al}_{5}{ }^{-}, \mathrm{Na}_{5} \mathrm{Al}_{5}{ }^{-}, \mathrm{Na}_{3} \mathrm{Al}_{12}{ }^{-}$, and $\mathrm{Na}_{4} \mathrm{Al}_{12}{ }^{-}$cluster anions. All values are in $\mathrm{eV}$. The calculated values for all low energy isomers are listed; the first listed value corresponds to the lowest energy isomer.

\begin{tabular}{|c|c|c|c|c|}
\hline \multirow[b]{2}{*}{ Cluster } & \multirow{2}{*}{$\begin{array}{l}\text { ADE } \\
\text { Theo. }\end{array}$} & \multirow{2}{*}{$\frac{\text { EA }}{\text { Expt. }}$} & \multicolumn{2}{|l|}{ VDE } \\
\hline & & & Theo. & Expt. \\
\hline $\mathrm{Na}_{2} \mathrm{Al}_{6}$ & $1.20,1.18,1.14$ & 1.20 & $1.63,1.47,1.41$ & 1.66 \\
\hline $\mathrm{Na}_{4} \mathrm{Al}_{5}$ & $1.41,1.68$ & 1.44 & $1.52,1.92$ & 1.55 \\
\hline $\mathrm{Na}_{5} \mathrm{Al}_{5}$ & $0.64,0.92$ & 0.57 & $0.89,1.02$ & 0.87 \\
\hline $\mathrm{Na}_{3} \mathrm{Al}_{12}$ & 2.04 & 2.08 & 2.31 & 2.43 \\
\hline $\mathrm{Na}_{4} \mathrm{Al}_{12}$ & 1.21 & 1.45 & 1.88 & 1.89 \\
\hline
\end{tabular}

shell species (see below), the spacing between the first two transitions in the photoelectron spectrum provides its HOMOLUMO gap. At $\sim 0.7 \mathrm{eV}$, this gap reflects the stability of neutral $\mathrm{Na}_{2} \mathrm{Al}_{6}$. Generally, the computational and experimental results are in good agreement.

Confirmation that the $\mathrm{Na}_{2} \mathrm{Al}_{6}$ neutral cluster, with its 20 valence electrons, exhibits electronic shell closure behavior is provided by its calculated FMO correlation diagram (see Figure 4). It shows that the levels group themselves into the

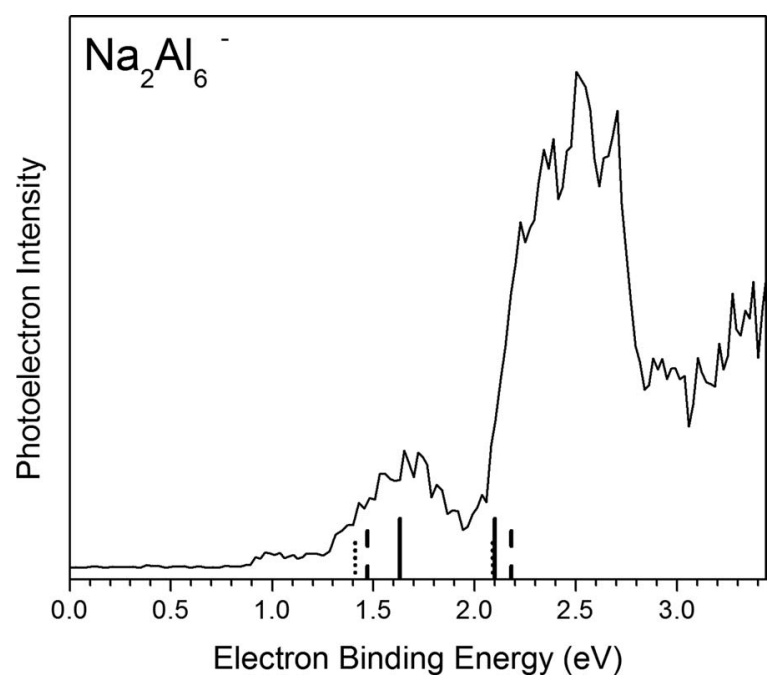

FIG. 3. Photoelectron spectrum of the $\mathrm{Na}_{2} \mathrm{Al}_{6}{ }^{-}$cluster anion. The overlaid stick spectra indicate the calculated first two transitions from the $\mathrm{Na}_{2} \mathrm{Al}_{6}{ }^{-}$ anion to its corresponding neutral cluster. (Solid sticks: isomer 1; dashed sticks: isomer 2; dotted sticks: isomer 3.) 


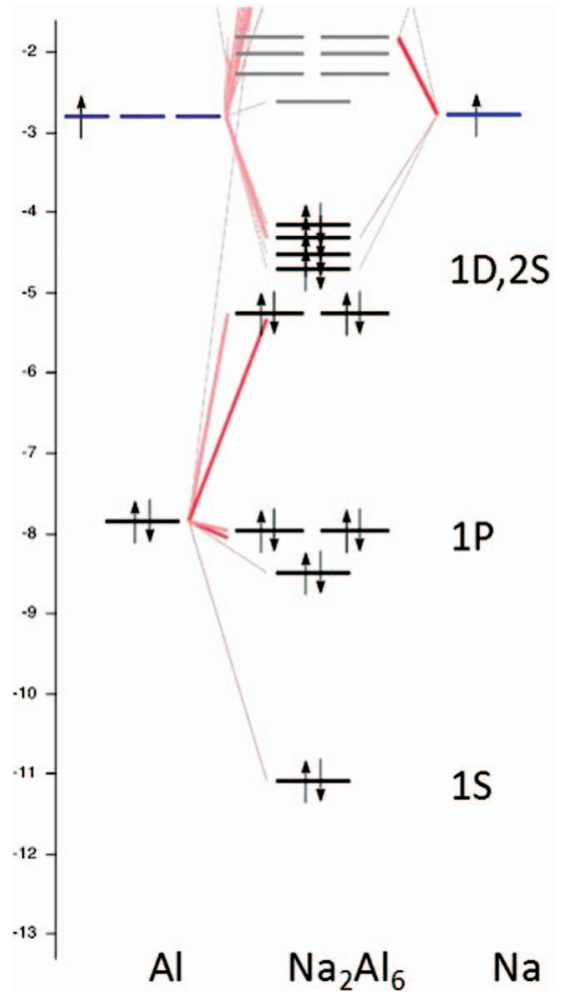

FIG. 4. The fragment molecular orbitals (FMO) analysis for the $\mathrm{Na}_{2} \mathrm{Al}_{6}$ neutral cluster.

1S, 1P, 1D/2S pattern expected under the jellium-like shell model $^{46}$ for free electron metals such as sodium and aluminum.

\section{B. $\mathrm{Na}_{4} \mathrm{Al}_{5}-/ \mathrm{Na}_{4} \mathrm{Al}$}

Figure 5 presents the computed structures of the two lowest energy isomers of $\mathrm{Na}_{4} \mathrm{Al}_{5}{ }^{-}$and $\mathrm{Na}_{4} \mathrm{Al}_{5}$ clusters. The lowest energy isomers of the $\mathrm{Na}_{4} \mathrm{Al}_{5}{ }^{-}$cluster anion, 7, and the neutral $\mathrm{Na}_{4} \mathrm{Al}_{5}$ cluster, $\mathbf{9}$, both adopt distorted octahedral-like structures, these being formed by an $\mathrm{Al}_{5}$ square pyramid and a sodium atom occupying one of the vertices. The remaining three sodium atoms cap triangular faces. The second lowest energy isomers of the cluster anion, $\mathbf{8}$, and the neutral cluster, 10, are also both made up of $\mathrm{Al}_{5}$ square pyramids. However, in each of these cases, all four of their sodium atoms bind to the base of their $\mathrm{Al}_{5}$ square pyramids. Also, notice that while the energy difference between anion's two isomer structures is quite small $(0.07 \mathrm{eV})$, the energy difference is significantly larger $(0.35 \mathrm{eV})$ between the neutral's two isomer structures.

As in $\mathrm{Na}_{2} \mathrm{Al}_{6}{ }^{-}$, the charge distributions in the isomers of the $\mathrm{Na}_{4} \mathrm{Al}_{5}{ }^{-}$cluster anion show that the majority of their excess electron resides on their aluminum moieties. Unlike $\mathrm{Na}_{2} \mathrm{Al}_{6}{ }^{-}$, however, the net charge transfer in $\mathrm{Na}_{4} \mathrm{Al}_{5}{ }^{-}$to its $\mathrm{Al}_{5}$ moiety differs considerably from isomer to isomer, with $\mathrm{Al}_{5}$ in 7 receiving $-3.27 e$ but with $\mathrm{Al}_{5}$ in 8 getting only $-2.51 e$. The difference may be due to the relatively symmetric location of the four sodium atoms around the $\mathrm{Al}_{5}$ moiety in isomer 7, compared with the asymmetric location of sodium atoms around this moiety in isomer $\mathbf{8}$. In the case of the neutral $\mathrm{Na}_{4} \mathrm{Al}_{5}$ cluster, the charge distributions in isomers, $\mathbf{9}$ and
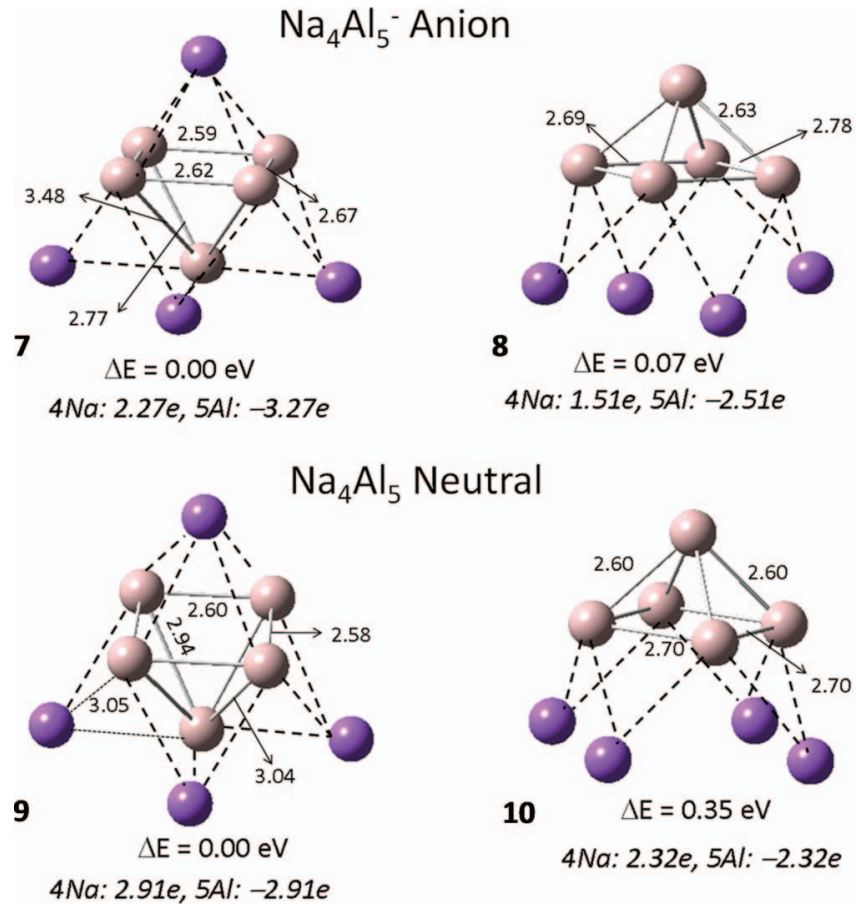

FIG. 5. The two lowest energy isomers of the $\mathrm{Na}_{4} \mathrm{Al}_{5}{ }^{-}$cluster anion and the $\mathrm{Na}_{4} \mathrm{Al}_{5}$ neutral cluster along with their relative energies, $\Delta \mathrm{E}(\mathrm{eV})$. Isomers $\mathbf{7}$ and $\mathbf{8}$ correspond to the $\mathrm{Na}_{4} \mathrm{Al}_{5}{ }^{-}$cluster anion, while $\mathbf{9}$ and $\mathbf{1 0}$ correspond to the lowest energy isomers of the neutral $\mathrm{Na}_{4} \mathrm{Al}_{5}$ cluster. The gray spheres represent aluminum atoms and the purple spheres represent sodium atoms. All the bond lengths are given in $\AA$. The calculated Natural Population Analysis (NPA) charges are given in italics below each isomer.

10, show that their $\mathrm{Al}_{5}$ moieties possess net negative charges of about $-2.9 e$ and $-2.3 e$, respectively, this difference as well being influenced by the relative positions of the sodium atoms around the $\mathrm{Al}_{5}$ moieties. These $\mathrm{Al}_{5}$ aluminum moieties are clearly Zintl anions. A trend is emerging whereby multiply charged aluminum cluster moieties, i.e., aluminum Zintl anions, are more likely to form in sodium-aluminum clusters when several sodium atoms are available.

Figure 6 presents the photoelectron spectrum of the $\mathrm{Na}_{4} \mathrm{Al}_{5}{ }^{-}$cluster anion. The first few sets of photodetachment transitions have been calculated for each of the two lowest energy isomers of the $\mathrm{Na}_{4} \mathrm{Al}_{5}{ }^{-}$cluster anion (7 and 8), and these are presented as stick spectra in Figure 6 (solid and dashed sticks are for transitions from $\mathbf{7}$ and $\mathbf{8}$, respectively). We have calculated ADE and VDE values for the lower energy transition in the cases of both isomer $\mathbf{7}$ and isomer $\mathbf{8}$ (see Table I). The VDE of 7 is $1.52 \mathrm{eV}$, and it matches well with the experimental value of $1.55 \mathrm{eV}$. On the other hand, the VDE of $\mathbf{8}$, which is $1.92 \mathrm{eV}$, is significantly higher in energy than the observed value. The ADE values follow similar trends. The $\mathrm{ADE}$ of $\mathbf{7} \mathrm{is} 1.41 \mathrm{eV}$, and this is close to the estimated value of $1.44 \mathrm{eV}$, whereas the ADE of $\mathbf{8}$ is $1.68 \mathrm{eV}$. Thus, it is likely that only isomer $\mathbf{7}$ is present in the cluster anion beam. Comparison of stick spectra for the two isomers with the experimental spectrum (see Figure 6) leads to the same conclusion.

In this system, the 20 valence electron, closed shell cluster is the $\mathrm{Na}_{4} \mathrm{Al}_{5}{ }^{-}$cluster anion. Figure 7 presents the calculated FMO correlation diagram for the $\mathrm{Na}_{4} \mathrm{Al}_{5}{ }^{-}$cluster anion. In a 20 valence electron cluster that obeys the jellium-like 


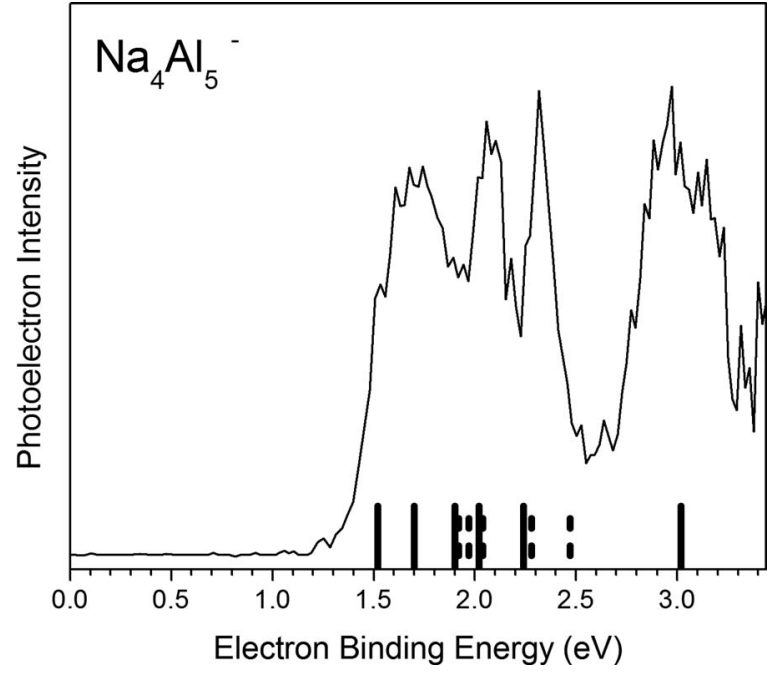

FIG. 6. Photoelectron spectrum of the $\mathrm{Na}_{4} \mathrm{Al}_{5}{ }^{-}$cluster anion. The overlaid stick spectra indicate the calculated low energy transitions from the $\mathrm{Na}_{4} \mathrm{Al}_{5}{ }^{-}$ anion to its corresponding neutral cluster. (Solid sticks: isomer 7; dashed sticks: isomer 8.)

model, one would expect the $1 S 1 P 1 D$ and $2 S$ levels to be filled. It is evident from Figure 7 that the expected 20 valence electron, shell-closing is observed. The resulting MO energy levels form three distinct blocks, with the lowest two blocks corresponding to $1 S$ and $1 P$, and with the frontier block encompassing $1 D$ and $2 S$. Because the $\mathrm{Na}_{4} \mathrm{Al}_{5}{ }^{-}$cluster anion is a closed shell species, it would be expected to exhibit high

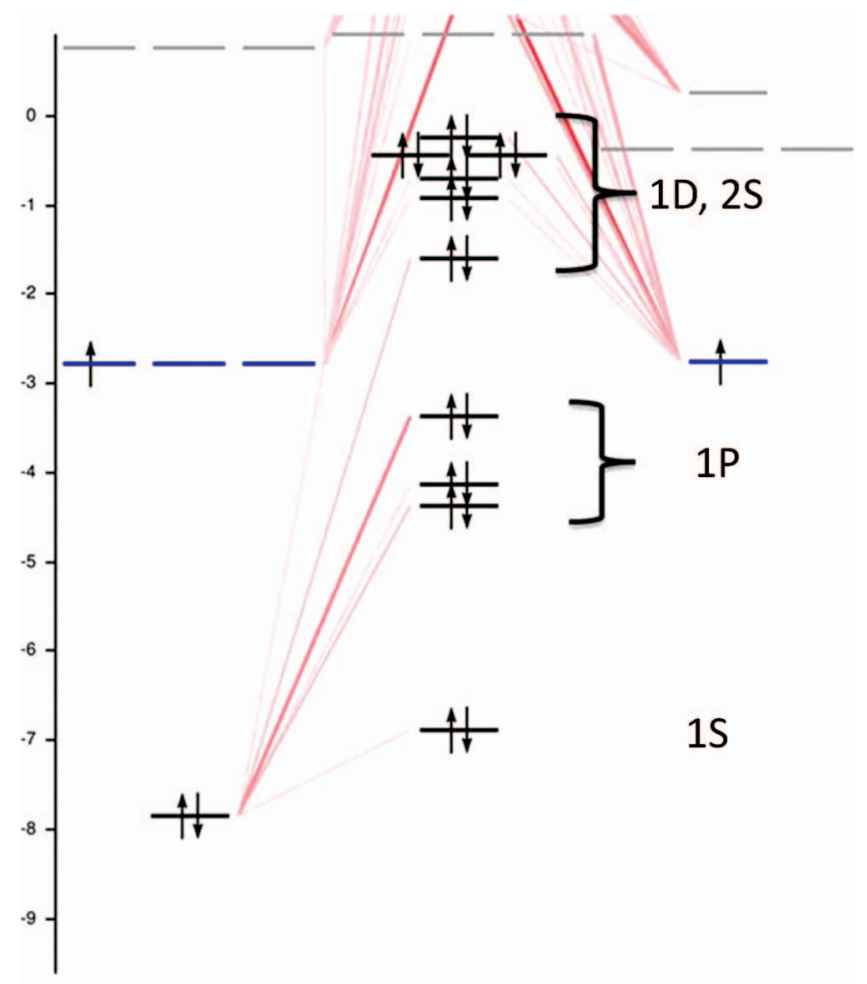

Al $\quad \mathrm{Na}_{4} \mathrm{Al}_{5}-\mathrm{Na}$

FIG. 7. The fragment molecular orbitals (FMO) analysis for the $\mathrm{Na}_{4} \mathrm{Al}_{5}{ }^{-}$ cluster anion.
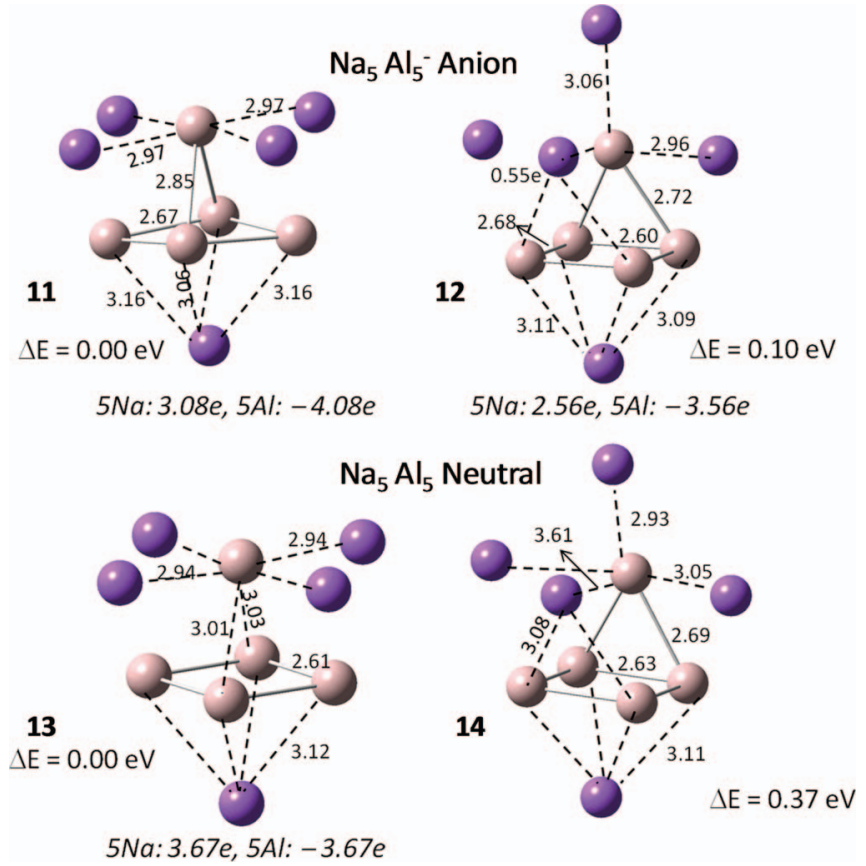

FIG. 8. The two lowest energy isomers of the $\mathrm{Na}_{5} \mathrm{Al}_{5}{ }^{-}$cluster anion and the $\mathrm{Na}_{5} \mathrm{Al}_{5}$ neutral cluster along with their relative energies, $\Delta \mathrm{E}(\mathrm{eV})$. Isomers 11 and 12 correspond to the $\mathrm{Na}_{5} \mathrm{Al}_{5}{ }^{-}$anion, while $\mathbf{1 3}$ and $\mathbf{1 4}$ correspond to the lowest energy isomers of neutral $\mathrm{Na}_{5} \mathrm{Al}_{5}$. The gray spheres represent aluminum atoms and the purple spheres represent sodium atoms. All the bond lengths are given in $\AA$. The calculated Natural Population Analysis (NPA) charges are given in italics below each isomer.

electron detachment energy. The fact that it does not may be due to excess negative charge accumulation on the $\mathrm{Al}_{5}$ moiety, causing a destabilization of the frontier orbitals and thereby reducing the shell-closing effects in this system.

\section{C. $\mathrm{Na}_{5} \mathrm{Al}_{5}-/ \mathrm{Na}_{5} \mathrm{Al}$}

The calculated structures of the lowest energy isomers of the $\mathrm{Na}_{5} \mathrm{Al}_{5}{ }^{-}$cluster anion (11 and 12) and of the $\mathrm{Na}_{5} \mathrm{Al}_{5}$ neutral cluster (13 and 14) are presented in Figure 8. As in the $\mathrm{Na}_{4} \mathrm{Al}_{5}{ }^{-}$cluster anion and the $\mathrm{Na}_{4} \mathrm{Al}_{5}$ neutral cluster, the $\mathrm{NaAl}_{5}$ sub-units in the lowest energy isomers of the $\mathrm{Na}_{5} \mathrm{Al}_{5}{ }^{-}$ cluster anion (11) and the $\mathrm{Na}_{5} \mathrm{Al}_{5}$ neutral cluster (13) also adopt distorted octahedral geometries, with the remaining sodium atoms occupying various positions around this central core. Not surprisingly, the relative energies of the isomers of $\mathrm{Na}_{5} \mathrm{Al}_{5}{ }^{-}$and $\mathrm{Na}_{5} \mathrm{Al}_{5}$ are also similar to those of $\mathrm{Na}_{4} \mathrm{Al}_{5}{ }^{-}$ and $\mathrm{Na}_{4} \mathrm{Al}_{5}$.

The $-3.67 e$ charge on the $\mathrm{Al}_{5}$ moiety of the $\mathrm{Na}_{5} \mathrm{Al}_{5}$ neutral cluster (structure 13) shows that it is a Zintl anion. It is interesting to compare isoelectronic sodium/aluminum clusters, such as the $\mathrm{Na}_{4} \mathrm{Al}_{5}{ }^{-}$cluster anion and the $\mathrm{Na}_{5} \mathrm{Al}_{5}$ neutral cluster, where the additional sodium atom in $\mathrm{Na}_{5} \mathrm{Al}_{5}$ provides the extra negative charge (extra electron) in $\mathrm{Na}_{4} \mathrm{Al}_{5}{ }^{-}$. In the $\mathrm{Na}_{4} \mathrm{Al}_{5}{ }^{-}$cluster anion (structure 7), the net charge on the $\mathrm{Al}_{5}$ moiety is $-3.27 e$, whereas in the similarly structured $\mathrm{Na}_{5} \mathrm{Al}_{5}$ neutral cluster (structure 13), it is $-3.67 e$. The actual negative charges on the $\mathrm{Al}_{5}$ moieties are comparable, regardless of the net charge state. Also, the net charge on the $\mathrm{Al}_{5}$ moiety of the $\mathrm{Na}_{5} \mathrm{Al}_{5}{ }^{-}$cluster anion is $-4.08 e$. The $\mathrm{Al}_{5}$ moiety has 


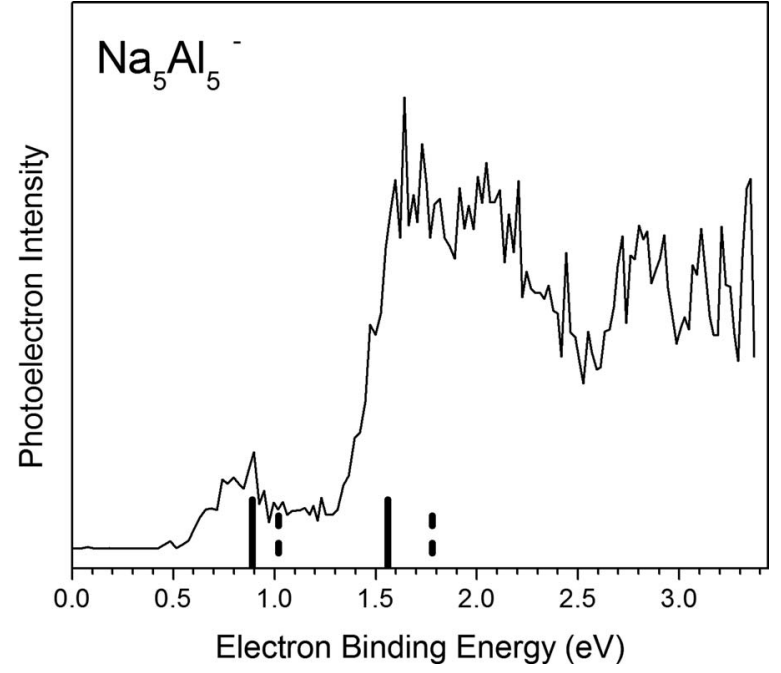

FIG. 9. Photoelectron spectrum of the $\mathrm{Na}_{5} \mathrm{Al}_{5}{ }^{-}$cluster anion. The overlaid stick spectra indicate the calculated first two transitions from the $\mathrm{Na}_{5} \mathrm{Al}_{5}{ }^{-}$ cluster anion to its corresponding neutral cluster. (Solid sticks: isomer 11; dashed sticks: isomer 12.)

a propensity for forming Zintl anions when paired with five sodium atoms.

The photoelectron spectrum of the $\mathrm{Na}_{5} \mathrm{Al}_{5}{ }^{-}$cluster anion is presented in Figure 9. The first two photodetachment transitions have been calculated for each of the two lowest energy isomers of the $\mathrm{Na}_{5} \mathrm{Al}_{5}{ }^{-}$anion (11 and 12), and these are presented as stick spectra in Figure 9 (solid and dashed sticks are for transitions from $\mathbf{1 1}$ and $\mathbf{1 2}$, respectively). We have calculated ADE and VDE values for the lower energy transition in the cases of both isomer $\mathbf{1 1}$ and isomer $\mathbf{1 2}$ (see Table I). The calculated VDE of $\mathbf{1 1}$ is $0.89 \mathrm{eV}$, and it compares well with the experimental value of $0.87 \mathrm{eV}$. On the other hand, the VDE of $\mathbf{1 2}$, which is $1.02 \mathrm{eV}$, is significantly higher in energy than the observed value. The ADE values follow similar trends. The calculated ADE of $\mathbf{1 1}$ is $0.64 \mathrm{eV}$, and this is close to the estimated EA value of $0.57 \mathrm{eV}$, whereas the ADE of $\mathbf{1 2}$ is $0.92 \mathrm{eV}$. This suggests that only isomer $\mathbf{1 1}$ may be present in the cluster anion beam, although the stick spectra are consistent with both being present. Since the neutral $\mathrm{Na}_{5} \mathrm{Al}_{5}$ cluster is a 20 valence electron, closed shell species (see below), the spacing between the first two transitions in the photoelectron spectrum of the $\mathrm{Na}_{5} \mathrm{Al}_{5}{ }^{-}$cluster anion reflects the HOMOLUMO gap of the neutral $\mathrm{Na}_{5} \mathrm{Al}_{5}$ cluster. At $\sim 0.7 \mathrm{eV}$, this gap reflects the stability of the closed shell $\mathrm{Na}_{5} \mathrm{Al}_{5}$ neutral cluster, just as it did in the case of neutral $\mathrm{Na}_{2} \mathrm{Al}_{6}$. The computational results show good agreement with the experimental photoelectron spectrum.

With 20 valence electrons, the $\mathrm{Na}_{5} \mathrm{Al}_{5}$ neutral cluster meets the condition for electronic shell closure. Figure 10 presents the calculated FMO correlation diagram for the $\mathrm{Na}_{5} \mathrm{Al}_{5}$ neutral cluster, where it exhibits three distinct blocks of MO energy levels, reflecting the $1 \mathrm{~S}, 1 \mathrm{P}, 1 \mathrm{D} / 2 \mathrm{~S}$ pattern expected under the jellium-like model for a closed shell species. Not surprisingly, the isoelectronic species, $\mathrm{Na}_{4} \mathrm{Al}_{5}{ }^{-}$ and $\mathrm{Na}_{5} \mathrm{Al}_{5}$ yield very similar, yet not identical FMO correlation diagrams (see Figures 7 and 10, respectively).

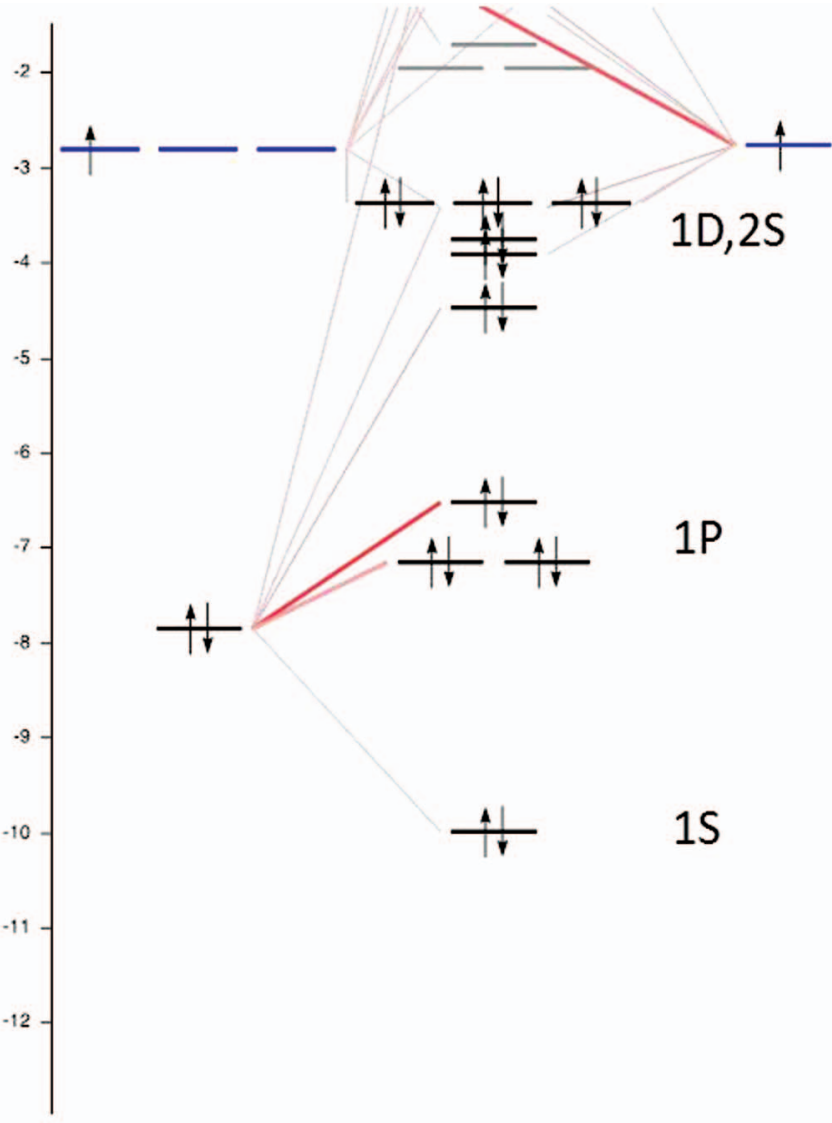

Al $\quad \mathrm{Na}_{5} \mathrm{Al}_{5} \quad \mathrm{Na}$

FIG. 10. The fragment molecular orbitals (FMO) analysis for the $\mathrm{Na}_{5} \mathrm{Al}_{5}$ neutral cluster.

\section{D. $\mathrm{Na}_{3} \mathrm{Al}_{12}-\mathrm{Na}_{3} \mathrm{Al} \mathrm{I}_{12}$}

Figure 11 presents the lowest energy structures of the $\mathrm{Na}_{3} \mathrm{Al}_{12}{ }^{-}$anion (15) and the $\mathrm{Na}_{3} \mathrm{Al}_{12}$ neutral (16). Both of these exhibit rhombohedral-like structures, with an aluminum atom at the center, a sodium atom at one of the apexes, and the remaining two sodium atoms capping the two adjacent fourmember rings. Other anion and neutral isomers of these clusters (not shown), where two sodium atoms cap two alternate four membered rings are also found to have energies which are close to those of the lowest energy structures. Substantial charge transfer to their $\mathrm{Al}_{12}$ moieties was found in both the $\mathrm{Na}_{3} \mathrm{Al}_{12}{ }^{-}$cluster anion $(-2.90 e)$ and in the $\mathrm{Na}_{3} \mathrm{Al}_{12}$ neutral cluster $\left(-2.17 e\right.$ ). The $\mathrm{Al}_{12}$ moiety within the $\mathrm{Na}_{3} \mathrm{Al}_{12}$ neutral cluster is a Zintl anion.

Figure 12 presents the photoelectron spectrum of the $\mathrm{Na}_{3} \mathrm{Al}_{12}{ }^{-}$cluster anion. The first photodetachment transition has been calculated for the lowest energy isomer of the $\mathrm{Na}_{3} \mathrm{Al}_{12}{ }^{-}$anion (15), and this is presented as a stick spectrum in Figure 12. We have calculated ADE and VDE values for this transition in the case of this isomer (see Table I). The calculated VDE is $2.31 \mathrm{eV}$, and it compares well with the experimental value of $2.43 \mathrm{eV}$. The calculated ADE is $2.04 \mathrm{eV}$, and this is close to the estimated EA value of $2.08 \mathrm{eV}$. The computational results show good agreement with the spectrum. 


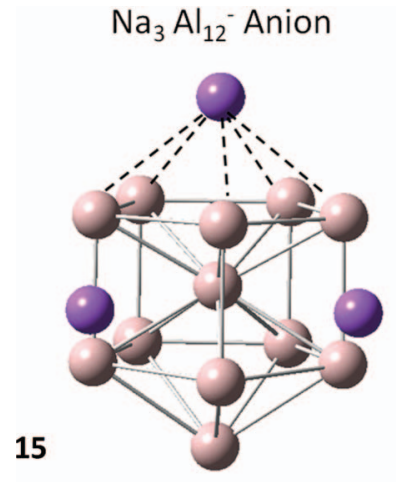

3Na: 1.90e, 12Al: $-2.90 e$

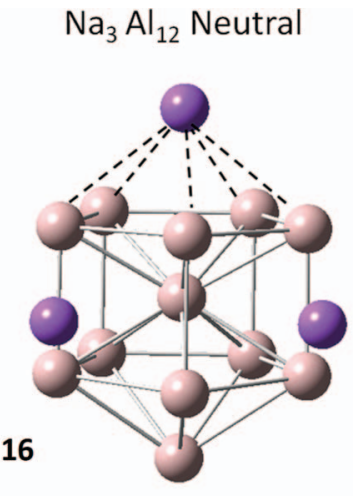

$3 \mathrm{Na}: 2.17 e, 12 \mathrm{Al}:-2.17 e$

FIG. 11. The lowest energy isomers of the $\mathrm{Na}_{3} \mathrm{Al}_{12}{ }^{-}$cluster anion (15) and the $\mathrm{Na}_{3} \mathrm{Al}_{12}$ neutral cluster (16). The gray spheres represent aluminum atoms and the purple spheres represent sodium atoms. The calculated Natural Population Analysis (NPA) charges are given in italics below each isomer.

The $\mathrm{Na}_{3} \mathrm{Al}_{12}{ }^{-}$cluster anion possesses 40 valence electrons, where 40, like 20, is an electronic shell closing, magic number. Figure 13 presents the calculated FMO correlation diagram for the $\mathrm{Na}_{3} \mathrm{Al}_{12}{ }^{-}$cluster anion. For 40 electrons, the expected filling order of the shells is $1 S 1 P 1 D 2 S 1 F 2 P$. As shown in Figure 13, the MO energy levels fall into four distinct blocks, corresponding to $(1 S),(1 P),(1 D, 2 S)$, and $(1 F, 2 P)$, thus supporting the expectation that the $\mathrm{Na}_{3} \mathrm{Al}_{12}{ }^{-}$ cluster anion conforms to a 40 valence electron shell closure. Furthermore, because $\mathrm{Na}_{3} \mathrm{Al}_{12}{ }^{-}$is a closed shell species, it is expected to exhibit a relatively high electron affinity, and with $\mathrm{ADE}$ and estimated EA values of $2.04 \mathrm{eV}$ and $2.08 \mathrm{eV}$, respectively, it does.

\section{E. $\mathrm{Na}_{4} \mathrm{Al}_{12}-/ \mathrm{Na}_{4} \mathrm{Al}_{12}$}

As shown in Figure 14, the $\mathrm{Na}_{4} \mathrm{Al}_{12}{ }^{-}$cluster anion adopts a capped icosahedral-like structure, with its missing ver-

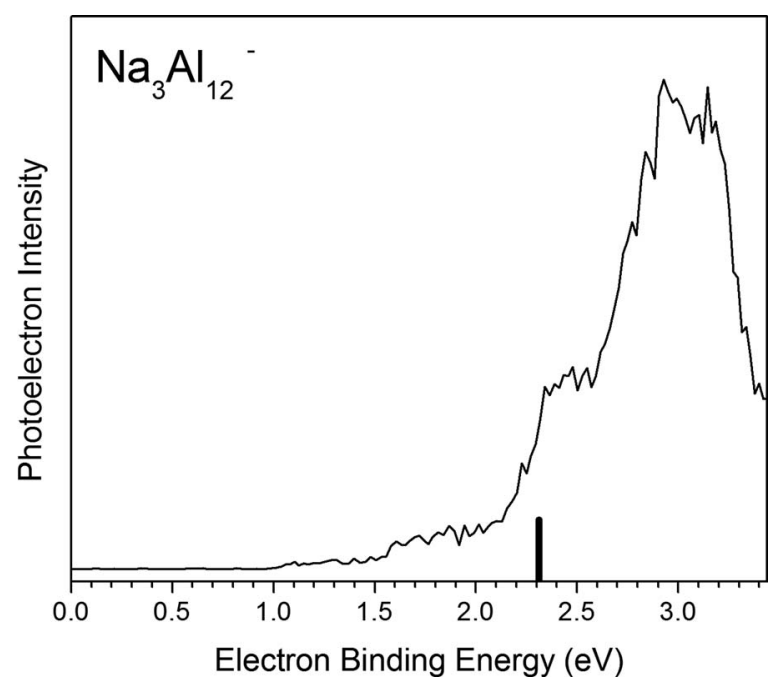

FIG. 12. Photoelectron spectrum of the $\mathrm{Na}_{3} \mathrm{Al}_{12}{ }^{-}$cluster anion. The overlaid stick spectra indicate the calculated transitions from the ground state of the $\mathrm{Na}_{3} \mathrm{Al}_{12}{ }^{-}$cluster anion to the ground state of the $\mathrm{Na}_{3} \mathrm{Al}_{12}$ neutral cluster.

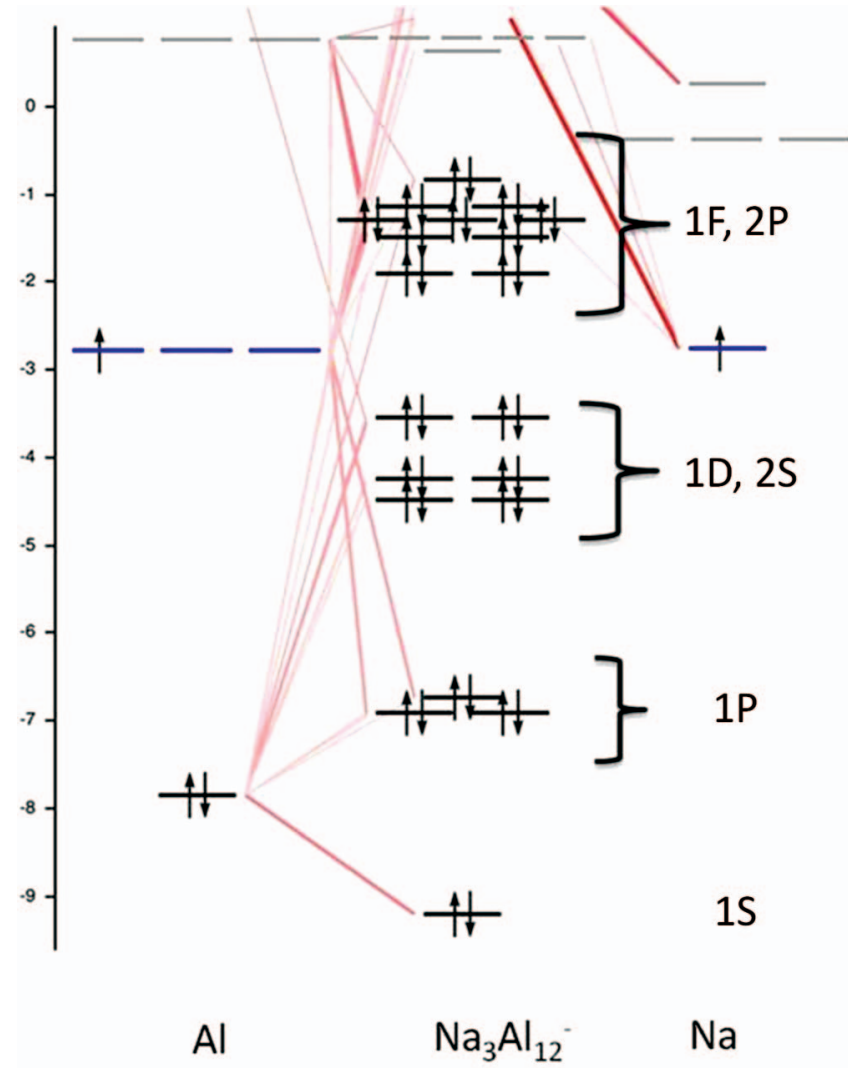

FIG. 13. The fragment molecular orbitals (FMO) analysis for the $\mathrm{Na}_{3} \mathrm{Al}_{12}{ }^{-}$ cluster anion.

tices occupied by sodium atoms (see structure 17), while the $\mathrm{Na}_{4} \mathrm{Al}_{12}$ neutral cluster exhibits a rhombohedral-like structure (see structure 18). The structure of the latter is, in fact, quite similar to that of its isoelectronic counterpart, the $\mathrm{Na}_{3} \mathrm{Al}_{12}{ }^{-}$ cluster anion, cf. structure $\mathbf{1 5}$.

Charge analyses of the $\mathrm{Na}_{4} \mathrm{Al}_{12}{ }^{-}$cluster anion and the $\mathrm{Na}_{4} \mathrm{Al}_{12}$ neutral cluster reveal net charges on their $\mathrm{Al}_{12}$ moieties of $-4.14 e$ and $-3.43 e$, respectively. Comparing the isoelectronic species, $\mathrm{Na}_{4} \mathrm{Al}_{12}$ and $\mathrm{Na}_{3} \mathrm{Al}_{12}{ }^{-}$, shows that the charges on their $\mathrm{Al}_{12}$ moieties are $-3.43 e$ and $-2.90 e$, respectively. It is interesting that the $\mathrm{Al}_{12}$ moiety within the $\mathrm{Na}_{4} \mathrm{Al}_{12}$ neutral cluster possesses more negative charge than

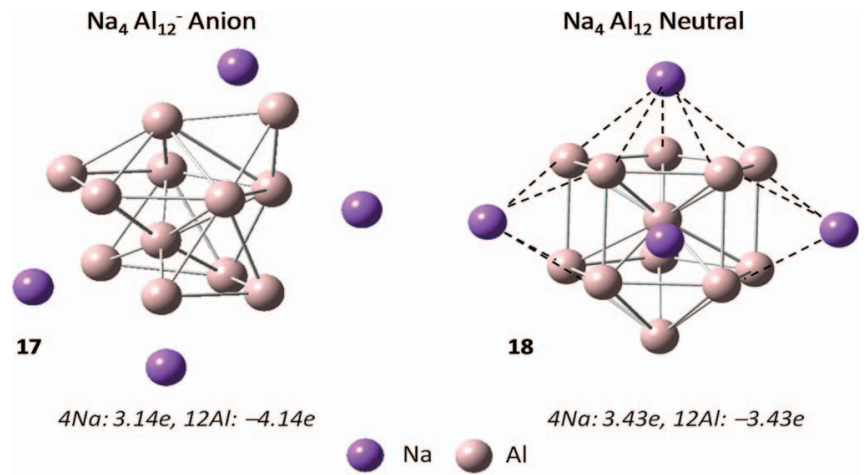

FIG. 14. The lowest energy isomers of the $\mathrm{Na}_{4} \mathrm{Al}_{12}{ }^{-}$cluster anion (17) and the $\mathrm{Na}_{4} \mathrm{Al}_{12}$ neutral cluster (18). The gray spheres represent aluminum atoms and the purple spheres represent sodium atoms. The calculated Natural Population Analysis (NPA) charges are given in italics below each isomer. 


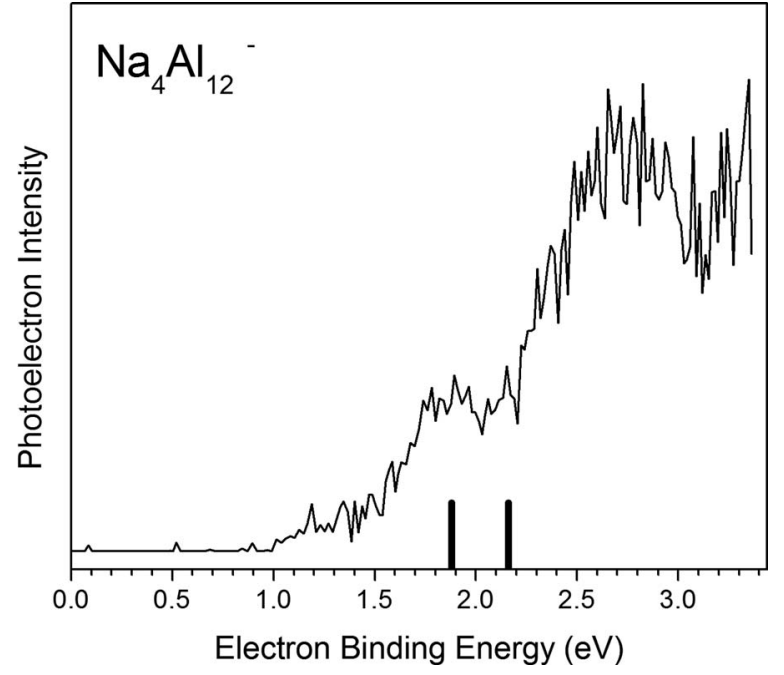

FIG. 15. Photoelectron spectrum of the $\mathrm{Na}_{4} \mathrm{Al}_{12}{ }^{-}$cluster anion. The overlaid stick spectra indicate the calculated transitions from the ground state of the $\mathrm{Na}_{4} \mathrm{Al}_{12}{ }^{-}$cluster anion to the ground and first excited states of the $\mathrm{Na}_{4} \mathrm{Al}-12$ neutral cluster.

the $\mathrm{Al}_{12}$ moiety within the $\mathrm{Na}_{3} \mathrm{Al}_{12}{ }^{-}$cluster anion. The $\mathrm{Al}_{12}$ moiety within the $\mathrm{Na}_{4} \mathrm{Al}_{12}$ neutral cluster is a robust Zintl anion.

Figure 15 presents the photoelectron spectrum of $\mathrm{Na}_{4} \mathrm{Al}_{12}{ }^{-}$cluster anion. The first two photodetachment transitions have been calculated for the lowest energy isomer of the $\mathrm{Na}_{4} \mathrm{Al}_{12}{ }^{-}$anion, 17, and these are presented as a stick spectrum in Figure 15. We have also calculated ADE and VDE values for the lower energy transition in the case of this isomer (see Table I). The calculated VDE is $1.88 \mathrm{eV}$, and it compares well with the experimental value of $1.89 \mathrm{eV}$. The calculated $\mathrm{ADE}$ is $1.21 \mathrm{eV}$, and this is in reasonable agreement with the estimated EA value of $1.45 \mathrm{eV}$. Since the $\mathrm{Na}_{4} \mathrm{Al}_{12}$ neutral cluster is a 40 valence electron, closed shell species (see below), the spacing between the first two transitions in the photoelectron spectrum of the $\mathrm{Na}_{4} \mathrm{Al}_{12}{ }^{-}$cluster anion reflects the HOMO-LUMO gap of the neutral $\mathrm{Na}_{4} \mathrm{Al}_{12}$ cluster. This computed HOMO-LUMO gap is $\sim 0.3 \mathrm{eV}$. It reflects the enhanced stability of the closed shell $\mathrm{Na}_{4} \mathrm{Al}_{12}$ neutral cluster, just as earlier discussed HOMO-LUMO gaps reflected the enhanced stabilities of the $\mathrm{Na}_{2} \mathrm{Al}_{6}$ and $\mathrm{Na}_{5} \mathrm{Al}_{5}$ neutral clusters. While the signal-to-noise ratio of the $\mathrm{Na}_{4} \mathrm{Al}_{12}{ }^{-}$cluster anion photoelectron spectrum leads to some degree of uncertainty, the calculated gap and observed spacing are broadly consistent.

The $\mathrm{Na}_{4} \mathrm{Al}_{12}$ neutral cluster possesses 40 valence electrons, where 40 is a magic number. Figure 16 presents the calculated FMO correlation diagram for the $\mathrm{Na}_{4} \mathrm{Al}_{12}$ neutral cluster. For 40 electrons, the expected filling order is $1 S 1 P$ $1 D 2 S 1 F 2 P$. As shown in Figure 16, the MO energy levels fall into four distinct blocks, corresponding to $(1 S),(1 P),(1 D$, $2 S)$, and $(1 F, 2 P)$, thus supporting the expectation that the $\mathrm{Na}_{4} \mathrm{Al}_{12}$ neutral cluster is a 40 valence electron closed shell species. Neutral $\mathrm{Na}_{4} \mathrm{Al}_{12}$ is a geometrically symmetrical, energetically stabilized cluster that is home to an $\mathrm{Al}_{12}$ moiety with a negative charge of $-3.43 e$, i.e., the multiply negatively charged Zintl anion, $\mathrm{Al}_{12}{ }^{3.43-}$.

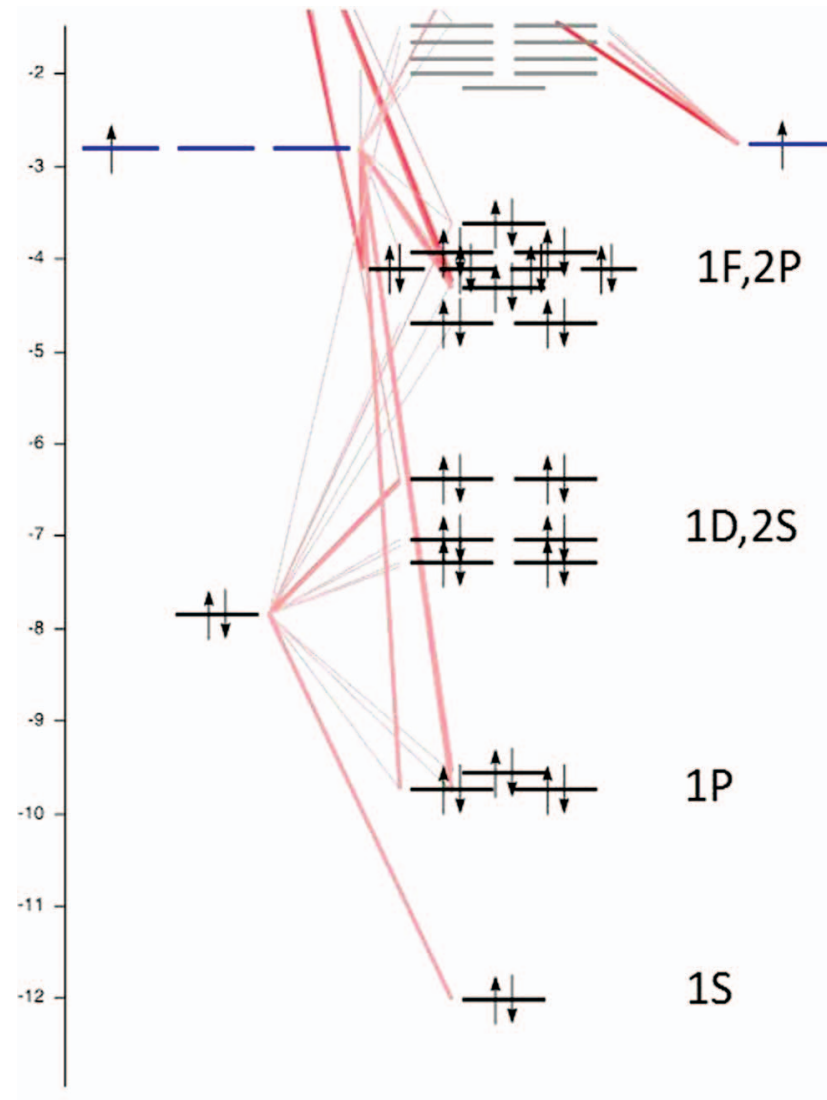

Al $\quad \mathrm{Na}_{4} \mathrm{Al}_{12} \quad \mathrm{Na}$

FIG. 16. The fragment molecular orbitals (FMO) analysis for the $\mathrm{Na}_{4} \mathrm{Al}_{12}$ neutral cluster.

\section{CONCLUDING REMARKS}

Through natural population (charge) analysis, we have established that the aluminum moieties within the sodium-aluminum clusters studied here are Zintl anions. Our computational results are validated by the good agreement between the values in Table I and between the computed stick spectra and their corresponding experimental photoelectron spectra. Roughly speaking, the charge on the aluminum moieties in the lowest energy isomers of both the neutral and the anionic sodium-aluminum clusters tends to be more negative for those clusters which possess larger numbers of sodium atoms. After all, sodium atoms are the primary sources of the electrons. Also, the differences between charges on the aluminum moieties in cluster anions and those on the aluminum moieties in their neutral cluster counterparts tend to be bigger, i.e., more negative, the larger the clusters' aluminum atom to sodium atom ratios. Furthermore, the charge distributions in sodium-aluminum cluster anions are consistent with those found in alkali and ammonium halide anions. ${ }^{55,56}$ In the latter cases, the halide anionic moieties, within the larger molecular anions, carry $-1 \mathrm{e}$ charge relative to their formally neutral alkali atom or ammonium radical partners. While the sodium moieties within sodium-aluminum cluster anions are not neutral and while their aluminum moieties carry more than one electron's worth of negative charge (they are Zintl anions), 
the aluminum moieties nevertheless carry a net -1 e negative charge relative to their positively charged sodium moieties, just as in the anions of simpler salts.

A salt-like lattice made up of multiply charged, aluminum cluster anions, i.e., aluminum Zintl anions, and a charge-balancing number of counter-cations might be expected to achieve high lattice stabilization (cohesion) energy and with it, the potential of forming a bulk ionic (cluster-assembled) material. Although such materials would be metastable in a thermodynamic sense, they might nevertheless be stable on a practical time scale. As bulk materials, these compositions would carry an overall charge of zero. Thus, the basic units/building blocks of these materials would need to be uncharged as well. For this reason, the characterization of aluminum Zintl anions in neutral sodium-aluminum clusters has been our focus in this work. The neutral sodiumaluminum clusters are simply more relevant, than are sodiumaluminum cluster anions, for making a cluster-assembled material. Moreover, neutral sodium-aluminum clusters that also exhibit closed electronic shell would make, because of their enhanced stability, particularly promising candidates as building blocks of imagined bulk materials. The neutral clusters, $\mathrm{Na}_{5} \mathrm{Al}_{5}$ and $\mathrm{Na}_{4} \mathrm{Al}_{12}$, not only meet this condition, but with charges of -3.67 and -3.43 , respectively, their aluminum moieties exhibit the highest negative charges seen in this work. These moieties are both robust aluminum Zintl anions.

Finally, two follow-on ideas come to mind. One involves utilizing more electropositive "atoms" than alkali metal atoms with which to form clusters with aluminum "Zintl" anions. Super-alkali molecules, such as $\mathrm{Li}_{3} \mathrm{O}$, are candidates. ${ }^{57}$ Another approach is to make use of sodium-aluminum cluster anions as building blocks. After all, some of them are closed shell species, and strictly speaking, their aluminum moieties are also Zintl anions. The way to do this might be to form neutral salt clusters which are made up of alkalialuminum cluster anions and electropositive atom cations, e.g., $\mathrm{Cu}^{+}\left(\mathrm{Na}_{\mathrm{m}} \mathrm{Al}_{\mathrm{n}}\right)^{-}, \mathrm{Mg}^{++}\left(\mathrm{Na}_{\mathrm{m}} \mathrm{Al}_{\mathrm{n}}\right)^{=}$, or $\mathrm{Li}^{+}\left(\mathrm{Cs}_{\mathrm{m}} \mathrm{Al}_{\mathrm{n}}\right)^{-}$.

\section{ACKNOWLEDGMENTS}

This material is based in part on work supported by the Air Force Office of Scientific Research (AFOSR) under Grant Nos. FA9550-11-1-0068 (K.H.B.) and FA9550-11-10171 (B.W.E.). K.H.B. and B.W.E. also thank the Defense Threat Reduction Agency (DTRA) for partial support under Grant No. HDTRA-1-12-1-007. B.K. acknowledges financial support from the BoR-RCS grant. PJ acknowledges partial support by the U. S. Department of Energy, Office of Basic Energy Sciences, Division of Materials Sciences and Engineering under Award \# DE-FG02-96ER45579. Resources of the National Energy Research Scientific Computing Center supported by the Office of Science of the U.S. Department of Energy under Contract No. DE-AC02-05CH11231 is also acknowledged.

${ }^{1}$ F. Laves, Naturwissenschaften 29, 244 (1941).

${ }^{2}$ W. Klemm and E. Busmann, Z. Anorg. Allg. Chem. 319, 297 (1963).

${ }^{3}$ Zintl Ions: Principle and Recent Developments, edited by T. F. Fassler (Springer-Verlag, Berlin, 2011).
${ }^{4}$ E. Zintl and W. Dullenkopf, Z. Phys. Chem. B 16, 183 (1932).

${ }^{5}$ J. D. Corbett, Chem. Rev. 85, 383 (1985).

${ }^{6}$ W. Klemm, Proc. Chem. Soc. 1958, 329 (1958).

${ }^{7}$ H. G. von Schnering, J. Wolf, D. Weber, R. Ramirez, and T. Meyer, Angew. Chem., Int. Ed. Engl. 25, 353 (1986).

${ }^{8}$ M. Reil and N. Korber, Z. Anorg. Allg. Chem. 633, 1599 (2007).

${ }^{9}$ C. Suchentrunk, J. Daniels, M. Somer, W. Carrillo-Cabrera, and N. Korber, Z. Naturforsch. B 60, 277 (2005).

${ }^{10}$ A. Spiekermann, S. D. Hoffmann, and T. F. Fassler, Angew. Chem., Int. Ed. Engl. 45, 3459 (2006).

${ }^{11}$ V. Queneau, E. Todorov, and S. C. Sevov, J. Am. Chem. Soc. 120, 3263 (1998).

${ }^{12}$ S. Joseph, C. Suchentrunk, F. Kraus, and N. Korber, Eur. J. Inorg. Chem. 2009, 4641 (2009).

${ }^{13}$ R. W. Farley and A. W. Castleman, J. Am. Chem. Soc. 111, 2734 (1989).

${ }^{14}$ R. W. Farley and A. W. Castleman, J. Chem. Phys. 92, 1790 (1990).

${ }^{15}$ W. J. Zheng, O. C. Thomas, J. M. Nilles, K. H. Bowen, A. C. Reber, and S. N. Khanna, J. Chem. Phys. 134, 224307 (2011).

${ }^{16}$ A. E. Kuznetsov, A. I. Boldyrev, X. Li, and L. S. Wang, J. Am. Chem. Soc. 123, 8825 (2001).

${ }^{17}$ L. F. Cui, X. Huang, L. M. Wang, D. Y. Zubarev, A. I. Boldyrev, J. Li, and L. S. Wang, J. Am. Chem. Soc. 128, 8390 (2006).

${ }^{18}$ L. F. Cui, X. Huang, L. M. Wang, J. Li, and L. S. Wang, J. Phys. Chem. A 110, 10169 (2006).

${ }^{19}$ J.-P. Dognon, C. Clabaguera, and P. Pyykko, Angew. Chem., Int. Ed. 46, 1427 (2007).

${ }^{20}$ A. Grubisic, H. Wang, X. Li, Y.-J. Ko, F. S. Kocak, M. R. Pederson, K. H. Bowen, and B. W. Eichhorn, Proc. Natl. Acad. Sci. U.S.A. 108, 14757 (2011).

${ }^{21}$ L.-F. Cui, X. Huang, L.-M. Wang, J. Li, and L. S. Wang, Angew. Chem., Int. Ed. 46, 742 (2007).

${ }^{22}$ U. Rohrmann, S. Schaefer, and R. Schaefer, J. Phys. Chem. A 113, 12115 (2009).

${ }^{23}$ D. E. Ellis, G. A. Benesh, and E. Byrom, Phys. Rev. B 16, 3308 (1977).

${ }^{24}$ A. Zunger, Phys. Rev. B 17, 2582 (1978).

${ }^{25}$ K. Kishio and J. O. Brittain, J. Phys. Chem. Solids 40, 933 (1979).

${ }^{26}$ N. E. Christensen, Phys. Rev. B 32, 207 (1985).

${ }^{27}$ R. Nesper, Angew. Chem., Int. Ed. Engl. 30, 789 (1991).

${ }^{28}$ A. Purath, R. Koppe, and H. Schnoeckel, Angew. Chem., Int. Ed. 38, 2926 (1999).

${ }^{29}$ P. Henke, N. Trapp, C. E. Anson, and H. Schnoeckel, Angew. Chem., Int. Ed. 49, 3146 (2010).

${ }^{30}$ R. E. Leuchtner, A. C. Harms, and A. W. Castleman, J. Chem. Phys. 94, 1093 (1991)

${ }^{31}$ X. Li, H. Wu, X.-B. Wang, and L. S. Wang, Phys. Rev. Lett. 81, 1909 (1998).

${ }^{32}$ S. N. Khanna and P. Jena, Phys. Rev. B 51, 13705 (1995).

${ }^{33}$ F. Liu, M. Mostoller, T. Kaplan, S. N. Khanna, and P. Jena, Chem. Phys. Lett. 248, 213 (1996).

${ }^{34}$ S. N. Khanna, B. K. Rao, and P. Jena, Phys. Rev. B 65, 125105 (2002).

${ }^{35}$ A. Nakajima, K. Hoshino, T. Sugioka, T. Naganuma, T. Taguwa, Y. Yamada, K. Watanabe, and K. Kaya, J. Phys. Chem. 97, 86 (1993).

${ }^{36}$ K. Hoshino, K. Watanabe, Y. Konishi, T. Taguwa, A. Nakajima, and K. Kaya, Chem. Phys. Lett. 231, 499 (1994).

${ }^{37}$ W.-J. Zheng, O. C. Thomas, T. P. Lippa, S. J. Xu, and K. H. Bowen, J. Chem. Phys. 124, 144304 (2006).

${ }^{38}$ Y. J. Ko, A. Shakya, H. Wang, A. Grubisic, W. Zheng, M. Goetz, G. Gantefoer, K. H. Bowen, P. Jena, and B. Kiran, J. Chem. Phys. 133, 124308 (2010).

${ }^{39}$ O. C. Thomas, W.-J. Zheng, T. P. Lippa, S. J. Xu, and K. H. Bowen, J. Chem. Phys. 114, 9895 (2001).

${ }^{40}$ O. C. Thomas, W.-J. Zheng, and K. H. Bowen, J. Chem. Phys. 114, 5514 (2001).

${ }^{41}$ X. Li, A. E. Kuznetsov, H.-F. Zhang, A. I. Boldyrev, and L. S. Wang, Science 291, 859 (2001).

${ }^{42}$ A. E. Kuznetsov, A. I. Boldyrev, H. J. Zhai, X. Li, and L. S. Wang, J. Am. Chem. Soc. 124, 11791 (2002).

${ }^{43}$ A. E. Kuznetsov, K. A. Birch, A. I. Boldyrev, X. Li, H. J. Zhai, and L. S. Wang, Science 300, 622 (2003).

${ }^{44}$ A. Dhavale, D. G. Kanhere, S. A. Blundell, and R. R. Zope, Phys. Rev. B 65, 085402 (2002).

${ }^{45}$ N. Walsh, F. Martinez, G. Marx, and L. Schweikhard, Eur. Phys. J. D 43, 241 (2007). 
${ }^{46}$ W. D. Knight, K. Clemenger, W. A. de Heer, W. A. Saunders, M. Y. Chou, and M. L. Cohen, Phys. Rev. Lett. 52, 2141 (1984).

${ }^{47}$ F. M. Bickelhaupt and E. J. Baerends, in Reviews in Computational Chemistry, edited by K. B. Lipowitz and D. B. Boyd (Wiley, New York, 2000), Vol. 15, pp. 1-86.

${ }^{48}$ M. Gerhards, O. C. Thomas, J. M. Nilles, W. J. Zheng, and K. H. Bowen, J. Chem. Phys. 116, 10247 (2002).

${ }^{49}$ X. Li, A. Grubisic, S. T. Stokes, J. Cordes, G. F. Gantefoer, K. H. Bowen, B. Kiran, M. Willis, P. Jena, R. Burgert, and H. Schnoeckel, Science 315, 356 (2007).

${ }^{50}$ J. Ho, K. M. Ervin, and W. C. Lineberger, J. Chem. Phys. 93, 6987 (1990). ${ }^{51}$ M. J. Frisch, G. W. Trucks, H. B. Schlegel et al., GAUSSIAN 03, Revision C.02, Gaussian, Inc., Wallingford, CT, 2004.
${ }^{52}$ G. te Velde, F. M. Bickelhaupt, S. J. A. van Gisbergen, C. Fonseca Guerra, E. J. Baerends, J. G. Snijders, and T. Ziegler, J. Comput. Chem. 22, 931 (2001).

${ }^{53}$ C. Fonseca Guerra, J. G. Snijders, G. te Velde, and E. J. Baerends, Theor. Chem. Acc. 99, 391 (1998).

${ }^{54}$ ADF2013, SCM, Theoretical Chemistry, Vrije Universiteit, Amsterdam, The Netherlands, http://www.scm.com.

${ }^{55}$ T. M. Miller, D. G. Leopold, K. K. Murray, and W. C. Lineberger, J. Chem. Phys. 85, 2368 (1986).

${ }^{56}$ S. N. Eustis, D. Radisic, K. H. Bowen, R. A. Bachorz, M. Haranczyk, G. K. Schenter, and M. Gutowski, Science 319, 936 (2008).

${ }^{57}$ D. Wang, J. D. Graham, A. M. Buytendyk, and K. H. Bowen, J. Chem. Phys. 135, 164308 (2011). 